Portland State University

PDXScholar

Civil and Environmental Engineering Master's

Project Reports

Civil and Environmental Engineering

Fall 2016

\title{
Exploring Length-Based Vehicle Count Data
}

Byad Ahmed

Portland State University

Follow this and additional works at: https://pdxscholar.library.pdx.edu/cengin_gradprojects

Part of the Civil and Environmental Engineering Commons, and the Transportation Commons Let us know how access to this document benefits you.

Recommended Citation

Ahmed, Byad, "Exploring Length-Based Vehicle Count Data" (2016). Civil and Environmental Engineering Master's Project Reports. 31.

https://doi.org/10.15760/CEEMP.5

This Project is brought to you for free and open access. It has been accepted for inclusion in Civil and Environmental Engineering Master's Project Reports by an authorized administrator of PDXScholar. Please contact us if we can make this document more accessible: pdxscholar@pdx.edu. 


\section{Exploring Length-Based Vehicle Count Data}

\section{BY}

\section{BYAD AHMED}
A research project report submitted in partial fulfillment of the requirement for the degree of

\section{MASTER OF SCIENCE IN \\ CIVIL AND ENVIRONMENTAL ENGINEERING}

Project Advisor:

Christopher M. Monsere, PhD, PE

Portland State University

C)2016 


\section{ACKNOWLEDGMENTS}

Firstly, I am grateful to the GOD for the good health and well-being that were necessary to complete this scientific work. Secondly, I would like to express my deepest gratitude to my fabulous advisor Dr. Christopher Monsere for his guidance, support, inspiration, and direction; he has provided for my research. It was an honor to work with someone who evidently cares and helps his students. I also like to extend my appreciation to Dr. Kelly Clifton, Dr. Miguel Figliozzi, Karen Pop, Megan Falcone, and Portland State University for their continued support and encouragement throughout my Master's degree program and during the long road to the completion of this achievement. Additionally, my sincere gratitude to KRG Ministry of Higher Education and especially to Human Capacity Development Program (HCDP) for its sponsorship of this MS program. Finally, I would like to share this accomplishment with my close friends deserving my deepest thanks, especially, Mr. Feras Latif, Mr. Kamal Ahmed, and Mohammed Osman, as well as to my family members, for their help, support, and encouragement. I could not have done this without all of you. Thank you all. I love you all. 


\begin{abstract}
The development of Intelligent Transportation Systems (ITS) requires high-quality traffic information within most urban areas worldwide and there has been an increasing need to collect and monitor of traffic data. The backbone of the data collection systems in many urban areas are still point-based detectors (often inductive loops). Trucks, due to their slower speeds and maneuverability can have an impact on congestion and efficiency. In addition, freight patterns are important to understanding the transportation network in Portland, Oregon. Recent improvements in the sensor network and data delivery system has resulted in counts by vehicle length on the Portland freeway system. In this report, the analysis of vehicle counts for the month of July 2016 is done specifically at different times of the day for the various vehicle patterns but with the aim of establishing a reliable model from the freight mobility within the Portland region. A total of 19,952,087 records were available for analysis. Vehicles are binned by 20, 35, 60, and 120 feet. Vehicles over 20 feet are considered freight vehicles. This is further compared between working day and weekday. The daily and weekly averages are taken, and these assist into drawing conclusions from the established patterns. On average, $23 \%$ of the vehicles observed are freight vehicles. A relationship on the freight mobility trends is also derived from the lane flow and hourly flow analysis per lane. It was concluded from the empirical evaluation that freight carrying vehicles move slower than the non-freight vehicles. It was further evident from the results that there was more freight traffic flowing in the mid-days than in early mornings and late evenings.
\end{abstract}

Keywords: Freight, Mobility, Data, Traffic, Monitoring, Classification. 


\section{TABLE OF CONTENTS}

1. INTRODUCTION

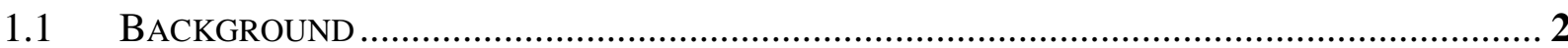

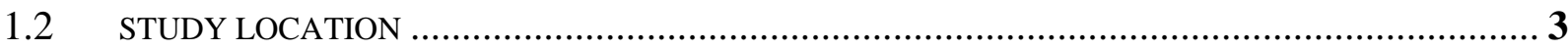

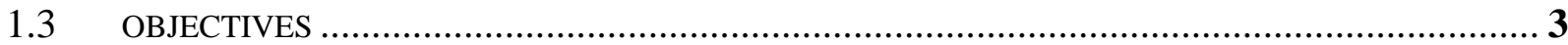

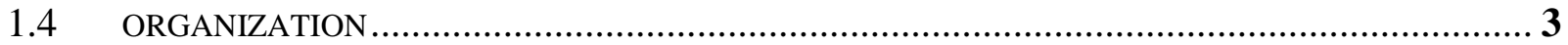

2. LITERATURE REVIEW ....................................................................................... 5

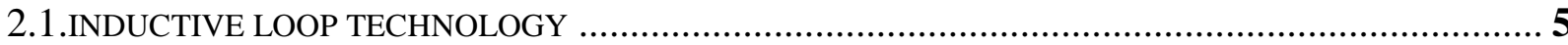

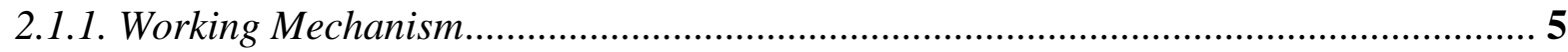

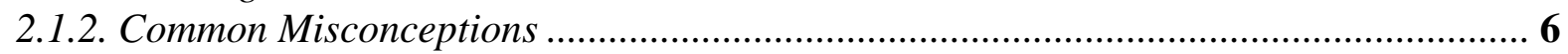

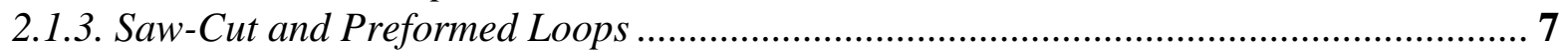

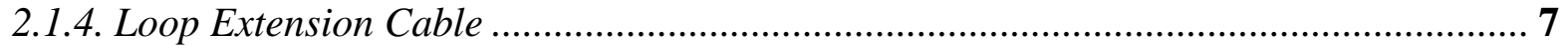

2.2. FREIGHT MOBILITY IN OREGON ……………………............................................... 7

2.3. MOBILITY AND CONGESTION PERFORMANCE MEASURES …………….............................. 8

3. DATA.................................................................................................................................. 10

4. METHODOLOGY AND ANALYSIS.............................................................................. 13

4.1 OREGON METRO CORRIDORS (STATION A AND B) ……………..................................... 14

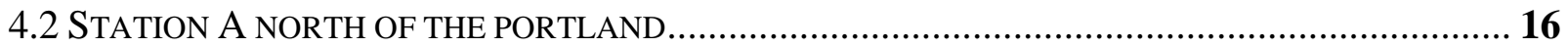

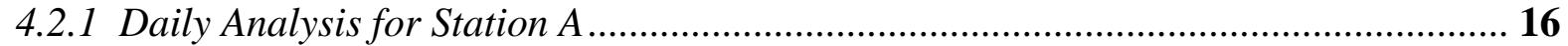

4.2.2 Station A Freight Mobility Analysis Weekly Counts $\backslash$ Weekly Average .......................... 19

4.2.3 Station A Freight Mobility Analysis (Work-Day)......................................................... 21

4.2.4 Station A Freight Mobility Analysis Weekend Day ................................................... 23

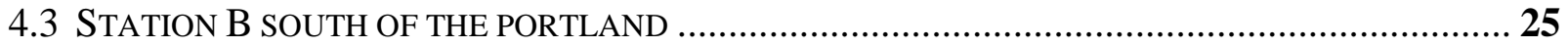

4.3.1 Daily Freight Mobility Analysis Station B ........................................................... 25

4.3.2 Station B Freight Mobility Analysis Weekly Counts $\backslash$ Weekly Average .......................... 28

4.3.3 Station B Freight Mobility Analysis (Work-Day)........................................................ 30

4.3.4 Station B Freight Mobility Analysis Weekend Day..................................................... 32

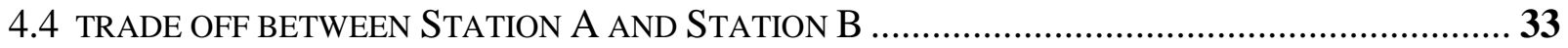

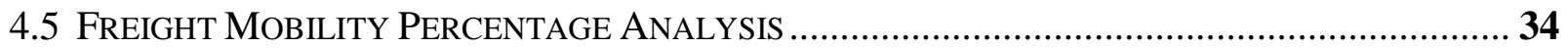

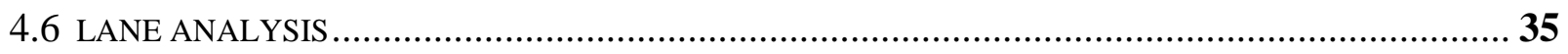

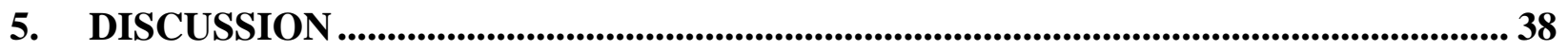

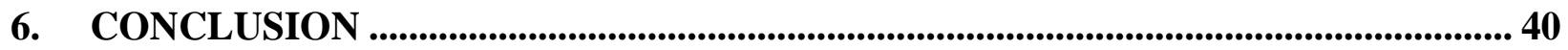

6.1 FUTURE RECOMMENDATIONS ........................................................................................ 41

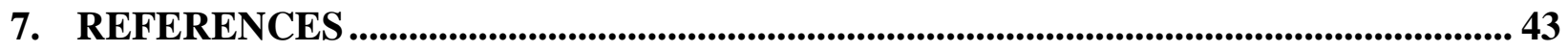




\section{LIST OF TABLES}

Table 1: Stations ID and Location.................................................................................................. 11

Table 2: Sample of ODOT Vehicle Length Classification Data ................................................ 12

Table 3: ODOT/PORTAL Vehicle Length Bins .................................................................. 13

Table 4: Percentage of Freight Analysis (Station A) ......................................................................... 18

Table 5: Percentage Number of Vehicles for Workdays................................................................. 21

Table 6: Percentage Vehicle Counts for the Weekend ............................................................... 25

Table 7: Percentage of Freight Daily Analysis (Station B) .......................................................... 27

Table 8: Working days Percentage Analysis for Station B .......................................................... 32

Table 9: Freight Mobility Percentage Analysis for Station B - Weekend ................................ 33

Table 10: Trade-off Between Station A and B ................................................................................. 34

Table 11: Percentage Freight Analysis - Group of Stations- Average ....................................... 35

Table 12: Lane Analysis for Freight and Non-Freight Vehicles .................................................. 37 


\section{LIST OF FIGURES}

Figure 1: The Loop Vehicle Detection ..................................................................................5

Figure 2: The bigger the vehicle the less the frequency change and vice versa ....................... 6

Figure 3: Portland Corridors 1 Analysis ( Source Metro- Atlas) .............................................. 14

Figure 4: Station A and B Locations (North and South of The Portland) ............................ 15

Figure 5: Transportation Flow shed ............................................................................................... 15

Figure 6: Station A, All Categories Mobility Pattern ............................................................. 17

Figure 7: Station A, Bin 2, 3, and 4 Mobility Pattern.............................................................. 17

Figure 8: Station A, Bins 2, 3, and 4 Daily Counts ............................................................. 18

Figure 9: Station A, Bin 1, Weekly Counts ...........................................................................19

Figure 10:Station A, Bin 2, 3, and 4 Weekly Counts ................................................................. 20

Figure 11:Station A, Bin 2, 3, and 4 Weekly Average Counts ................................................ 20

Figure 12:Station A, Bin-1 Counts in Thursday, July 28 2016 Workday ......................... 22

Figure 13:Station A, Bin 2, 3, and 4 Counts in Thursday, July $28^{\text {th }} 2016$ Workday ............ 23

Figure 14:Station A, Bin-1 Counts in Saturday, July 30 ${ }^{\text {th }} 2016$ Weekend day ...................... 24

Figure 15:Station A, Bin 2, 3, and 4 Counts in Saturday, July 30 2016 Weekend day.......24

Figure 16:Station B, All Categories Mobility Pattern ............................................................ 26

Figure 17:Station B, Bin 2, 3, and 4 Mobility Pattern ............................................................. 27

Figure 18:Station B, Bin 1 Weekly Counts.......................................................................................... 28

Figure 19:Station B, Bin 1 Weekly Average Counts.............................................................. 29

Figure 20:Station B, Bin 2, 3, and 4 Weekly Counts ......................................29

Figure 21:Station B, Bin 2, 3, and 4 Weekly Average Counts .............................................30

Figure 22:Station B, Bin-1 Counts in Tuesday, July $5^{\text {th }} 2016$ Work Day ............................. 31

Figure 23:Station B, Bin 2, 3, and 4 Counts in Tuesday, July $5^{\text {th }} 2016$ Work Day...........31

Figure 24:Station B, Bin 1 Counts in Saturday, July $9^{\text {th }} 2016$ Weekend Day....................32

Figure 25:Station B, Bin 2, 3, and 4 Counts in Saturday, July $9^{\text {th }} 2016$ Weekend Day.......33

Figure 26:Trade-off between Station $A$ and B, Combination of Bins 2, 3, and 4 Counts ....34

Figure 27:Lane Analysis, Station A, Bins 2, 3, and 4 Counts at July $2^{\text {nd }} 2016 \ldots . . . . . . . . . .37$ 


\section{INTRODUCTION}

Traffic data collection and monitoring are one amongst the most applicable and effective approaches to the ever increasing traffic congestion menace. It is believed that a thorough study on the same will help in the improvement of freight efficiencies and minimization of traffic congestions on the roads. Traffic monitoring information relating to the travel time, classification of vehicles, vehicle occupancy, speed and weight of trucks has been collected and closely monitored. In most urban environments, classification and collection of vehicle data have been limited. This is attributed to the high associated costs and difficulties to do with the use of automated equipment. The collected information may be absorbed for various reasons like the design of highways, planning, enforcement and research.

For purposes of planning, however, the impediment is usually with the characterized evasions by most truck drivers. The patterns of most truck movements are associated with high turning radii and heavyweight. For the operation of traffic, characterization of vehicles is very phenomenal even for planning and safety purposes. Owing to this relevance, most researchers have devised original truck data collection and visualization techniques, and this forms the basis for this research. Several approaches exist for detecting and classifying the vehicle length data collected. These include video image detection, travel surveys, and dual/single loop detectors. This research focuses on the classifications of trucks with basis on the length. Also, data from the inductive loop sensors together with the impacts from the classifications of traffic monitoring programs within Oregon State. The Portland City region of this state is the primary study focus where freight mobility is considered. 


\subsection{Background}

Worldwide, there is an increasing trend in the traffic data. This has triggered the need for most metropolitan areas to adapt and invent traffic monitoring programs as a bid to managing the ever growing traffic data. Due to this ever growing need, many research works have consequently been directed into this breadth with the view of understanding the traffic monitoring concepts and deriving the most efficient among the programs. The study conducted in this research narrows down to freight mobility in Oregon State, the city of Portland region and more accurately, some stations have already installed loop- vehicles detectors on the Interstate 5 or close to. According to the recently conducted research, it was established that the projected increase in the passenger and freight traffic within the city would significantly result into significant annual losses averaging 1.7 billion dollars by 2025 (Daily and Wall, 2003).

Congestions and delays in the freight industry are so undesirable due to their negative effects on businesses. Recommendations emerged from previously conducted studies that proper and more efficient tools for traffic monitoring and assessment be developed. These would enable planners to evaluate and monitor on how the transportation facilities operate efficiently. The measures of performance may include reliability of the travel time, speed and travel time. Earlier on, the actions were focused on passenger vehicles and less on freight traffic which was never incorporated independently. There, however, is a paradigm shift by most agencies from performance measures that are unique to an all-inclusive performance measure.

The efficiency of freight movement has an impact on everyone in every community. The efficient supply and movement of essential materials like office supplies, fuel, clothing, hardware, passenger cars among other material is key (Traffic detector, 1997). The effective mobility of freight, however, is not without some constraints. There are slowdowns to this which make the movement to ultimately be more costly (Zhang et al., 2005). These could be technical which might involve vehicle registration, insurance acquisition, registration of drivers, availability of loading facilities, or the most commonly incurred constraints are delays due from traffic congestion, traffic conflicts with other users on the road and traffic intersection/signaling geometrics. As a means of making freight mobility more efficient, technology has been incorporated into the freight data monitoring systems which primarily aims at continuously 
identifying and monitoring freight mobility. Some of these approaches are discussed in this document (Zhang, et al., 2007).

\subsection{Study Location}

The focus of this study was the Portland region. The case cities of concern were the Interstate 5 freeway and Portland city. Two group of stations were picked in the south and north of the city, and it is from these that the collected data was analyzed and discussed. The Interstate 5 freeway is characterized with a lot of truck traffic hence a critical trade corridor of the country. Considering this, I-5 was a perfect choice for the study conducted. From one recent report from FHWA (Federal Highway Administration), the stretches on the I-5 emerge as the topmost bottlenecks for trucks traversing the country's freeways. It is estimated that close to 1.3 million delay hours in the city accrue from these steep grades. There is an estimated further increase of freight/passenger traffic congestion in the coming years which if not controlled; it would lead to significant losses. Interstate 5 is on the West Coast of the United States. It serves some of the largest cities on the west coast of the country, including Portland, and has emerged as a significant trade corridor and top freight route of the country.

\subsection{Research Objectives}

The objective of this Research with the following objectives;

1) To explore how the length-based observations of vehicle counts might be used in a freight management system.

2) To explore the time-of-day and lane-by-lane variations in freight traffic.

\subsection{Organization}

The report is arranged in seven chapters. The introduction is descriptive of the background behind this study, the location of the reviewed study is described in this chapter as well. Here, a brief study of the Interstate 5 freeway close to Portland City is done. Also the chapter one describes the objectives of this study. These are related to the underlying freight monitoring \mobility concepts as well as the usefulness of truck classification data. Previous literature studies were reviewed in chapter two. This chapter elaborates on the use of the inductive loop technology for vehicle monitoring. The technology's operation mechanism is 
defined and the associated concepts illustrated. This aims to provide a baseline for the study being conducted. The data sources are described in chapter three of this research. Chapter four is the methodology $\backslash$ Analysis chapter where the collected data is analyzed graphically in agreement with the objectives of the study. These include classification of the trucks from the monthly counts. The relationships between these and mobility are further reviewed here. Chapter five encompasses discussions from the results and about the relevant literature works. The conclusion is summarized in Chapter six of the report and it's include the future study recommendations. Finally, chapter seven lists the references used for the research. 


\section{LITERATURE REVIEW}

\subsection{Inductive Loop Technology}

A number of approaches exist for vehicle detection. These range from the ultrasonic detection to the hose-style detection. The most reliable and recommended technology for drivethru or traffic control is the inductive loop technology. This section previews this technology from the working mechanisms to the underlying misconceptions.

\subsubsection{Working Mechanism}

The loop vehicle detection system has three main components. These are; a preformed/saw-cut loop, a detector, and a loop extension cable. During the installation and repair of inductive loop systems, minor details would dictate the reliable the system would be when detecting vehicles. For this reason, detailed attention is so crucial when troubleshooting and installing a loop detector. The figure 1 below schematically illustrates the three components. The saw-cut/preformed loop is first-of-all buried beneath the traffic lane, (Zhang et al., 2005). This is a wire run entering and exiting the same point location. The loop wire's ends are connected to the extension cable that connects with the vehicle detector as figure one illustrates, (Daily and Wall, 2003). The loop is then powered by the detector resulting in a magnetic field creation around the area of the loop.

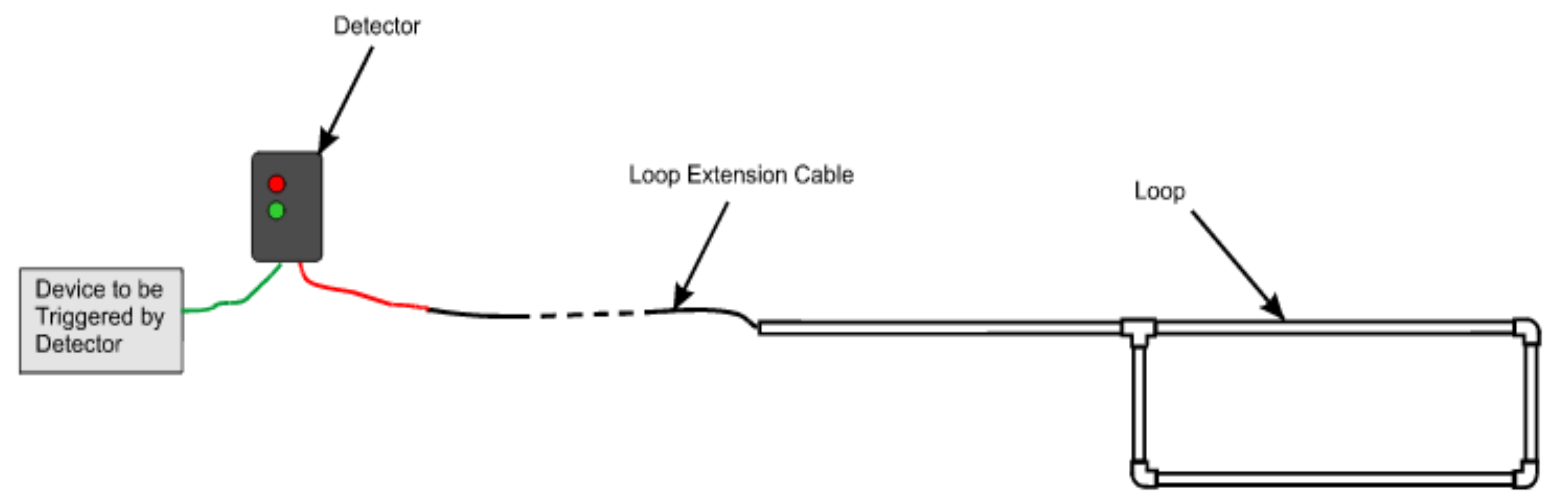

Figure 1: The Loop Vehicle Detection

Consequently, there occurs a constant frequency resonation of the loop which is proportional to what is being monitored by the detector. When there is no vehicle going over the loop, there is an establishment of a base frequency. There is an increase in the resonating frequency whenever a 
heavy object/vehicle goes over the loop. The consequent increase is sensed. With some detector designs, the sensed increase triggers the continued closure of the open relays until the time the vehicle will depart from the loop. The frequency then gets back to the base level. The relay has the capability for triggering multiple devices like a gate, audio intercom system or a traffic light. Generally speaking, a full-size vehicle would result into less frequency increase when compared to a more compact vehicle. An explanation for this is because the surfaces of the metals on the vehicle's undercarriage are much proximal to the loop. See Figure 2.

It is worthy and interesting to point out that the change in frequency for similar vehicle model and make is so consistent to the essence that the detector could be designed to detect the exact vehicle type going over the loop.
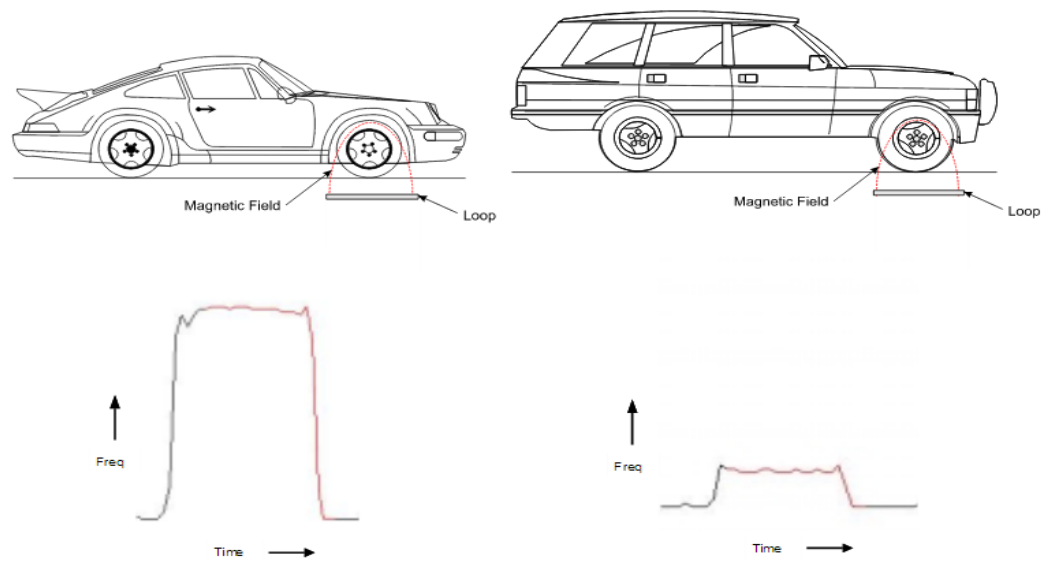

Figure 2: The bigger the vehicle the less the frequency change and vice versa

\subsubsection{Common Misconceptions}

Some people have believed that this vehicle technology performs detection with basis on the mass of the metal. This is so untrue. On the contrary, the detection mechanism lays basis to the surface area of the metal. This could also be termed as the skin effect. The frequency increases with the increased surface area along the loop plane. For instance, one foot thick and the one-foot square hunk of metal would have similar effects as a sheet metal of one square foot in a similar loop plane. This is an absolutely significant principle to always recall when dealing with the inductive loop detectors. 


\subsubsection{Saw-Cut and Preformed Loops}

The loop may be made of three to five loop wire turns encased within a PVC pipe. If this is the case, then the loop is pre-formed. Normally, the wire loop is 14 to 16 AWG, stranded and insulated with cross-linked polyethylene and is PVC encased for holding the shape of the loop and for loop wire protection from damages during pavement construction/installation. A saw-cut loop, on the other hand, is employed on an already pavement. The shape of the loop is incised on the pavement surface with the help of a concrete saw. The wire is then laid in the slot, pressed on a backer-rod poly-form for compacting the wire. A loop sealant is then filled to protect the loop wire (Chen and May 2003).

\subsubsection{Loop Extension Cable}

The significance of this is the extension of the distance between the vehicle detector and the loop. The extension cable's characteristics resemble the loop wires, and these must be soldered. The length may be extended safely up to $300 \mathrm{ft}$. if a good extension cable is used. This should, however, be counterchecked with the manufacturer of the detector (Chen and May 2003)

\subsection{Freight Mobility in Oregon}

Oregon's economy depends highly on freight transportation due to the state's geographic location. There is an estimated further increase of freight/passenger traffic congestion in the coming years which if not controlled (Nihan, 2002); it would lead to significant losses. Interstate 5 is on the West Coast of the United States crossing the State of Oregon and has emerged as a significant trade corridor and top freight route of the country. This spans through Josephine, Douglas and Jackson Counties of Northern Oregon past rugged mountains having steep grades, (Park et al., 2006). From one recent report from FHWA (Federal Highway Administration), the stretches on the I-5 emerge as the topmost bottlenecks for trucks traversing the country's freeways. It is estimated that close to 1.3 million delay hours in the city accrue from these steep grades. In the early 1990s, the Metropolitan Planning Organizations and states were obligated to include freights into their planning activities (Nihan, 2002). The main factors for inclusion were the ports' access points, crossings for international borders, airports, main routes for freight distribution and intermodal facilities for transportation (Coifman, 2010). It was required that there be supporting technical efforts for provision of analysis on the movement problem areas of 
services and goods as elaborated in the appropriate involvement of the private sector. The factor for explicit inclusion was the improvement of efficiency in freight movement (Jacobson et al., 2011). Consequently, TEA 21 propagated the significance of freight movements whereas AMATS acknowledged the mobility of freight to be a very important element for the process of planning. The 1997 update on the LRTP (Anchorage Bowl Long-Range Transportation Plan) encompassed an overall illustration of the movement of freight in anchorage (Chen and May, 2003). Truck movement constraints and traffic were also addressed. Identification of the expected impacts of the proposed improvements on selected problems was also done. Prior research works have justified the necessity for lead agencies for successful collection of regional data (Chen and May, 2003). Existing systems like the ATMS have been helpful so far albeit some impediments. For instance, systems of ATMS type have a poor loop placement plan. For this reason, they would need expensive and extensive retrofitting. Additional detectors would also be needed for the system's traffic data volume to be meaningful (Chen and May, 2003). For this reason, ATMS detectors haven't been adequate in loop maintenance and data monitoring. In Portland, pooling efforts and data collection focus on the good will spirit, trust and mutual respect between the agencies and concerned individuals. Conducted research works in the region favored the need for more successful programs of data collection within Oregon.

\subsection{Mobility and Congestion Performance Measures}

Speed and travel time data for trucks may be obtained using GPS data, Loop sensors at the roadways and weigh in motion data. There are however challenges and advantages when using this data for mobility and congestion monitoring (Smith and Collins, 2013). The use of loop sensors' archived data has succeeded in the estimation of freeway performances. The loop sensors may be used to study both non-recurring and recurring congestion as well as to identify the available regional bottlenecks. This technology is however limited in its differentiation ability of the types of vehicles (Chen and May, 2003). Modal disaggregate data provision is not possible with this technique. Research findings showed that there were possibilities of integrating single loop-detectors with video footages in a bid to differentiate the freight vehicles from the general purpose vehicles with the desired speed estimates and accuracy. Use of dual

loop detectors, however, sufficed as being less reliable and limited in the estimation ability of the types of vehicles during congestion (Chen and May, 2003). 
The truck transponder and weigh-in-motion data approaches were initially investigated by the Washington University. In their study, the researchers found out that the truck transponder and GPS approaches have the possibility to accurately estimate the travel times (Daily and Wall, 2003). These, however, demand high vehicle observation numbers but must incorporate techniques to determine those trucks that have halted to make deliveries or to refuel. Portland State University recently studied the adoption of trucks that was equipped with transponders. They estimated the time between the weigh stations of rural Oregon and the research was successful as far congestion and non-mobility measures' of performance development were concerned.

In the recent, the FHWA (Federal Highway Administration) together with the ATRI (American Trucking Research Institute) availed an online tool for measurement of freight performance- the FPMweb. This made it possible for the users to access the aggregated truck speed data with the help of GPS information from thousands of different trucks. This, however, had an issue with accuracy in most cases and where the traffic volume was low, there were fewer observations made. 


\section{DATA}

Traffic length-based data was obtained from ODOT (Oregon Department of Transportation) on the freeway sensors from the Region's online data archive: PORTAL, https://portal.its.pdx.edu/home. This portal is comprised of automatically archived vehicle classification data and the portal has two visualization graphical interfaces. The visualizations on the interfaces were enhanced mainly to predict whether the traffic percentage at a particular location is non-freight or freight. The visualizations also assist in describing the freight transport portion at a given location over time and whether this has changed with respect to time. At the portal's website, there is a detailed user manual on the data derivation and manipulation. Freight data displaying alongside the travel data was done for similar roadways since this was helpful as a normalization or calibration tool. This information is then useful to the targeted users and helps in traffic understanding. The primary source of data derived from the portal was the classification of vehicle length and vehicle speed.

From this online portal, it was possible to specify the station of interest, the range of data needed and the desired measure. For instance, vehicle counts data over a given period on the freeway sensors installed surrounding the Portland city was specified and downloaded. The data comprised of a huge excel file collected from 33 stations from the study area as shown in Table 1 below. The data of interest was occupancy, speed, and volume of traffic flow for trucks or cars. This was then separated and sorted with the help of R and Python software tools. This data was output from the currently most innovative technology for traffic data collection- the Inductive Loop Detection System. The deployment of the same along the studied traffic freeways made it possible for the collection to be feasible. In Portland, there are networks of Loop Detectors along the Interstate 5 freeway which grasp the real-time traffic information/data and store the same into their advanced systems of traffic monitoring. Along the Interstate 5 Freeway, more than 620 Loop Stations have been installed for this specific purpose. These are embedded along the pavements specifically for data collection.

Table 3 below gives a summary of the vehicle length bins as defined by the Oregon Department of Transportation (ODOT) from the PORTAL. From the two groups of stations in the data used for this research, two stations were picked too, one from each group. Station A 
where it's ID is (\#185- Columbia Blvd SB) in the north of the Portland, and station B where it's ID is (\#157- Capital Hwy NB) which is located in the south of the city of Portland.

Table 1: Stations ID and Location

\begin{tabular}{|c|c|c|c|}
\hline Station \# & Longitude & Latitude & Station ID \\
\hline 7 & -122.7860099 & 45.46795601 & Denney Rd NB \\
\hline 8 & -122.789555 & 45.4766092 & Allen Blvd NB \\
\hline 67 & -122.674134 & 45.50259162 & Front Ave SB \\
\hline 68 & -122.6730131 & 45.50006231 & Macadam Ave NB \\
\hline 69 & -122.6737076 & 45.49342673 & Hood Ave SB \\
\hline 81 & -122.7467057 & 45.39716034 & Lower Boones NB \\
\hline 82 & -122.7439037 & 45.41362379 & Carman to I-5 NB \\
\hline 83 & -122.7439666 & 45.42017752 & ORE 217/Kruseway NB \\
\hline 87 & -122.744163 & 45.4072569 & Upper Boones SB \\
\hline 88 & -122.7477944 & 45.42284223 & OR $217 /$ Kruse Way to SB I-5 \\
\hline 155 & -122.7440633 & 45.43510742 & Haines St NB \\
\hline 156 & -122.7406938 & 45.4425829 & Pacific Hwy W NB \\
\hline 157 & -122.7203863 & 45.45347617 & Capital Hwy NB \\
\hline 159 & -122.6943448 & 45.46596987 & Multnomah Blvd NB \\
\hline 166 & -122.6785005 & 45.55445871 & Going St NB \\
\hline 167 & -122.6784354 & 45.5619972 & Alberta St NB \\
\hline 168 & -122.6785749 & 45.57237747 & Portland Blvd NB \\
\hline 170 & -122.6828715 & 45.59270465 & Delta Park NB \\
\hline 171 & -122.6821721 & 45.60547851 & Marine Dr NB \\
\hline 173 & -122.7443411 & 45.43402906 & Haines St SB \\
\hline 174 & -122.7442217 & 45.43781682 & ORE 99W SB \\
\hline 177 & -122.665675 & 45.53287877 & Wheeler SB \\
\hline 179 & -122.6756767 & 45.54416868 & Greeley Ave SB \\
\hline 180 & -122.6787281 & 45.55492781 & Going St SB \\
\hline 181 & -122.678697 & 45.55756784 & Alberta St SB \\
\hline 182 & -122.6786798 & 45.56872903 & Portland Blvd SB \\
\hline 183 & -122.6786881 & 45.5769314 & Lombard EB to SB \\
\hline 184 & -122.6786818 & 45.57855418 & Lombard WB to SB \\
\hline 185 & -122.6795922 & 45.58477058 & Columbia Blvd SB \\
\hline 186 & -122.6834183 & 45.59349573 & I-5 SB at Victory \\
\hline 187 & -122.6828459 & 45.60415409 & Marine Dr/99e to SB I-5 \\
\hline 232 & -122.5462787 & 45.57415191 & EB Airport Way (2R057) to NB I-205 \\
\hline 355 & -122.6790506 & 45.46974679 & Terwilliger Blvd NB \\
\hline
\end{tabular}


A sample of ODOT vehicle length classification data for one of the stations (Station 185) in the north of Portland city as illustrated in Table 2 below. Here the number \# in the first column represent the sequence record data in the CSV file for the whole month data file, and second column is the station ID, while third column is for the lane number. Fourth column includes the type of bin number, fifth column for bin counts, and finally sixth column is for the time and date of the record sequences.

Table 2: Sample of ODOT Vehicle Length Classification Data

\begin{tabular}{|c|c|c|c|c|c|}
\hline$\#$ & Stationid & Lane & Bin_number & Bin_count & Bin_time \\
\hline 7586 & 185 & 14 & 2 & 0 & 7/1/2016 0:03 \\
\hline 7587 & 185 & 1 & 4 & 2 & 7/1/2016 0:04 \\
\hline 7589 & 185 & 2 & 1 & 4 & 7/1/2016 0:04 \\
\hline 7595 & 185 & 2 & 4 & 0 & 7/1/2016 0:05 \\
\hline 8304 & 185 & 1 & 3 & 0 & $7 / 1 / 20160: 03$ \\
\hline 8308 & 185 & 14 & 3 & 0 & 7/1/2016 0:03 \\
\hline . & . & . & . & . & . \\
\hline . & . & . & . & . & . \\
\hline 2736565 & 185 & 2 & 3 & 0 & $7 / 2 / 201618: 43$ \\
\hline 2736566 & 185 & 3 & 3 & 0 & 7/2/2016 18:43 \\
\hline 2736567 & 185 & 14 & 3 & 0 & $7 / 2 / 2016$ 18:43 \\
\hline 2736568 & 185 & 1 & 3 & 0 & $7 / 2 / 201618: 43$ \\
\hline . & . & . & . & . & . \\
\hline . & . & . & . & . & . \\
\hline 18772088 & 185 & 3 & 4 & 0 & $7 / 29 / 201619: 48$ \\
\hline 18772089 & 185 & 1 & 2 & 1 & $7 / 29 / 201619: 48$ \\
\hline 18772092 & 185 & 3 & 4 & 0 & 7/29/2016 19:49 \\
\hline . & . & . & . & . & . \\
\hline . & . & . & . & . & . \\
\hline 19955422 & 185 & 3 & 2 & 0 & $7 / 31 / 201623: 47$ \\
\hline 19955423 & 185 & 2 & 4 & 1 & $7 / 31 / 201623: 48$ \\
\hline 19955424 & 185 & 3 & 2 & 0 & $7 / 31 / 201623: 49$ \\
\hline 19955425 & 185 & 2 & 4 & 1 & $7 / 31 / 201623: 49$ \\
\hline 19955426 & 185 & 3 & 2 & 0 & $7 / 31 / 201623: 50$ \\
\hline
\end{tabular}




\section{METHODOLOGY AND ANALYSIS}

The results were studied in four data bins as defined by the Oregon Department of Transportation (ODOT). The major reason for this was to determine the freight and non-fright mobility patterns in Portland region. Focus was on long vehicles and the freight movement which were represented as the percentage of the traffic flow stream.

The first bin length (Bin 1) consists of the 'small' vehicle types. These short-unit vehicles are pickups and cars of length between 0 to 20 feet. Bin 2 vehicle types length was 21 to 35 feet length of vehicles (pulling trailers), cars and single unit trucks that were longer. Bin 3 consisted of combination trucks of length ranging from 36 to 60 feet. Finally, the last bin four was composed of multi-trailer trucks of length ranging from 61 to 120 feet long. Bins 2, 3, and 4 results and trends were generalized to represent long vehicle categories. This ensured allinclusiveness of the freight and non-freight vehicle types which were covered and formed the objectives' baseline. In this section, the monthly trends were analyzed from the truck classification data. The individual bin counts and the relationships between the different bin types were also analyzed. Station A (\#185) in the study represents the north of Portland city. Station B (\#157) represented south of Portland as shown in Figure 4. The average trends for both the working days and the weekends were also analyzed and the trends compared amongst the bins. The weekly averages for the same were also analyzed. The relationships between the vehicle mobility and the peak days and hours for both the bins were also discussed. VMT values from the ODOT database were also picked for the Interstate 5 freeway in the study area.

Table 3: ODOT/PORTAL Vehicle Length Bins

\begin{tabular}{|c|c|c|c|}
\hline $\begin{array}{c}\text { Bin } \\
\text { Number }\end{array}$ & $\begin{array}{c}\text { Bin } \\
\text { Length }\end{array}$ & Vehicle Types & \\
\hline 1 & $0-20 \mathrm{ft}$ & Cars, pickups, and short single-unit trucks & \\
\hline 2 & $21-35 \mathrm{ft}$ & Cars and trucks pulling trailers, long signle-unit trucks & \\
\hline 3 & $36-60 \mathrm{ft}$ & Combination trucks & \\
\hline 4 & $61-120 \mathrm{ft}$ & Multi-trailer trucks & \\
\hline
\end{tabular}




\subsection{Oregon Metro Corridors (Station A and B)}

As seen in Figure 5, traffic flow in the north and south of Portland were studied with reference to the mobility flow Atlas. The studied station A is central of the route to Vancouver and B to Tigard as shown in figure 4. Interstate 5 is encompassed in station A. The I5 allows intraregional, interstate and interregional movement of goods and people. It also emerges from the Atlas site that there is an integrated grid connection of the road networks which makes it possible for an individual to gain access to commercial stations and residential areas. This is part of what will explain the reason for the observed traffic trends in the region. In the corridor area, there is a significantly large amount of open, industrial and open space. From the Atlas site, it is estimated that 4 per cent of the corridor area is utilized for commercial purposes, 17 per cent for mixed-use commercial, 27 per cent for purely industrial, 31 per cent for residential purposes and the remaining 18 and 1 per cent for open/park spaces and rural areas respectively. It also suffices that most of the available population in Portland is the working class with more than half majority falling above the middle class category. It also turns out that there is a constant flow in/out trend of the work force in and out of Portland. Most of this population lives and works in different zones hence the need for daily commuting to and from the residences and work places. Figure 3 includes all these above.

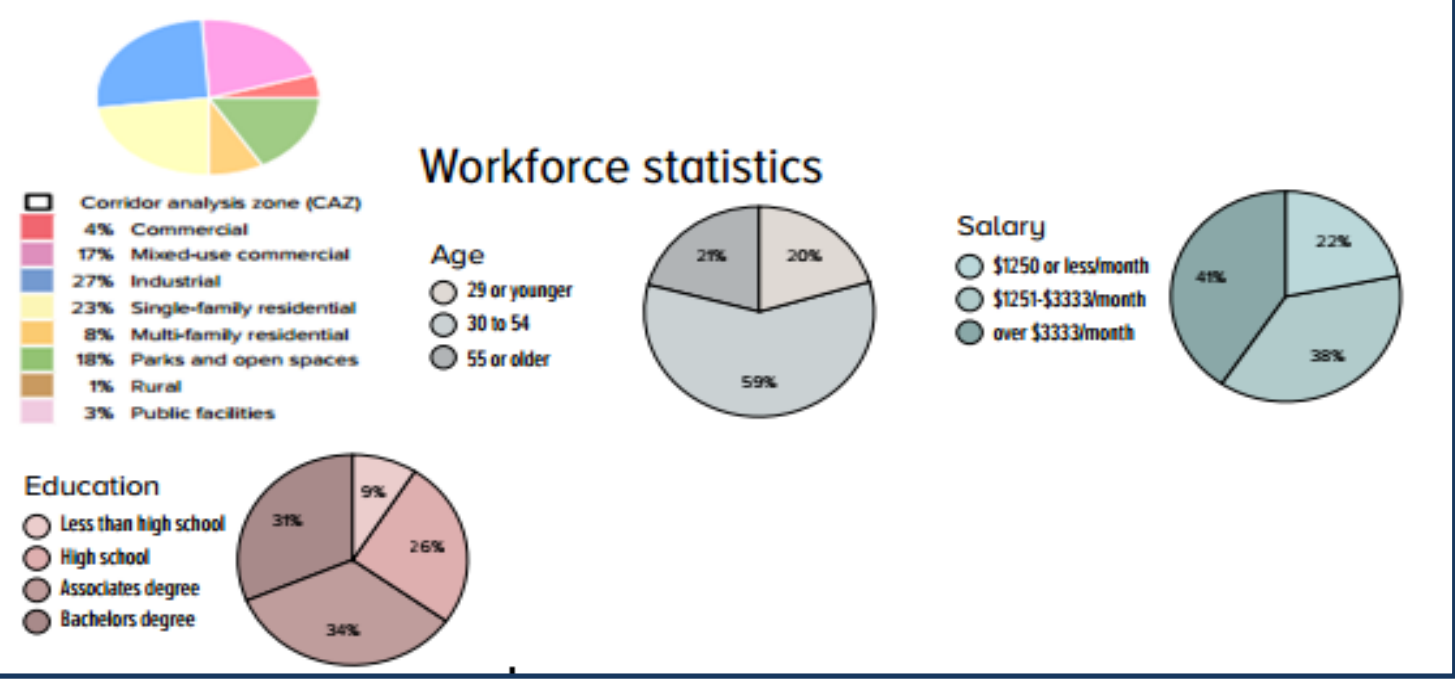

Figure 3: Portland Corridor 1 Analysis (Source Metro-Atlas) 


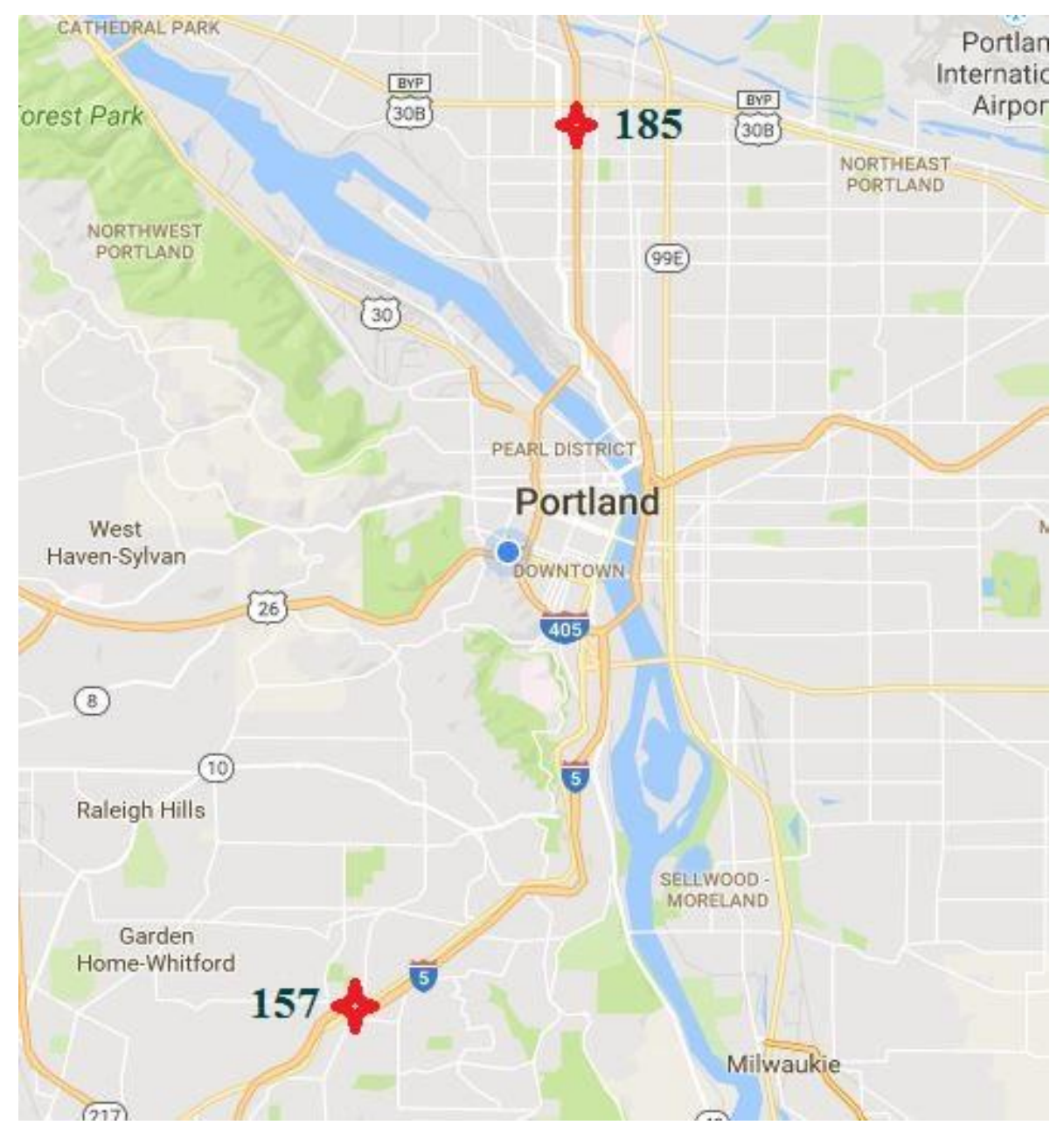

Figure 4: Station A and B Locations
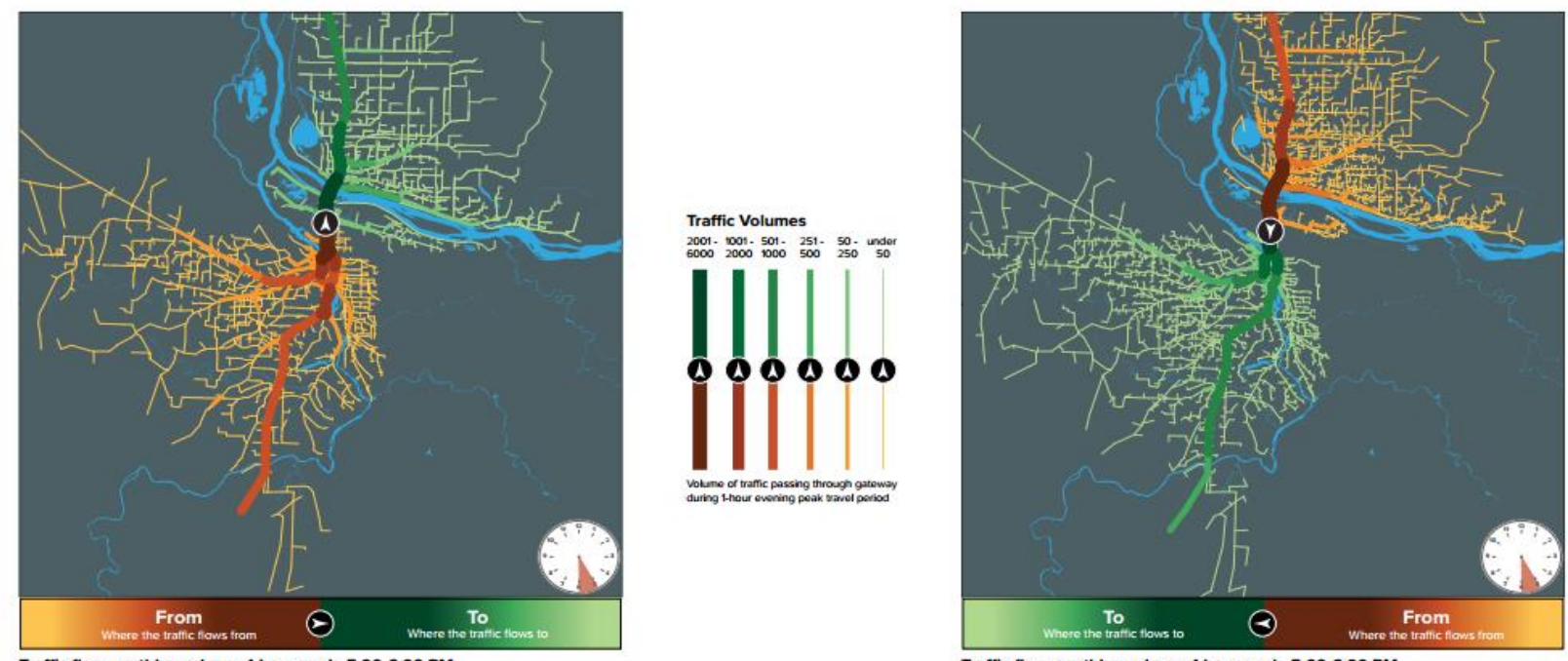

Figure 5: Transportation Flow shed 
The figure 5 from the Atlas metro Atlas website (2006), suggests a busy flow of traffic in and out of Portland. There is heavy traffic flow at the intersections and main highways. The traffic intensity reduces as the roads become narrower. The illustrations by figure 6 suggest the movement of traffic between the $1700 \mathrm{hrs}$ and $1800 \mathrm{hrs}$ peak hour. Understanding and appreciating this is so additive to the knowledge on the analyzed traffic count patterns at the station points. From the findings illustrated, the below sections proceed to explain the mobility patterns for the specific vehicle categories. Much focus is directed towards the long vehicles and freight mobility in relation to the small vehicles which apparently were dominant in Portland.

\subsection{Station A North of the Portland}

\subsubsection{Daily Analysis for Station A}

For the month of July, the plotted results for both vehicle categories at corridor 1 of station A were plotted as shown below. Freight and long vehicles mobility over the month was so low and the least when compared to the small vehicles (bin 1). Comparatively, the trend was flat throughout the month for bin 2, 3 and bin 4. There were more long vehicle counts (bin 4) than bin 3 type albeit the small disparity as evidenced in figure 6. Bin 2 was highest than 3 and 4 trends. The high mobility for bin 1 categories is a recipe for congestion characteristic in the north of Portland over the years. This has led to delays especially for the freight vehicles (bin 2, 3 and 4) hence discouraging freight mobility traversing through the north of Portland. Long vehicles on the other hand contribute to traffic congestions in the Portland and elsewhere around the world. This makes the legislators and concerned parties to opt for other routes with less traffic impact and more optimal freight mobility options. 


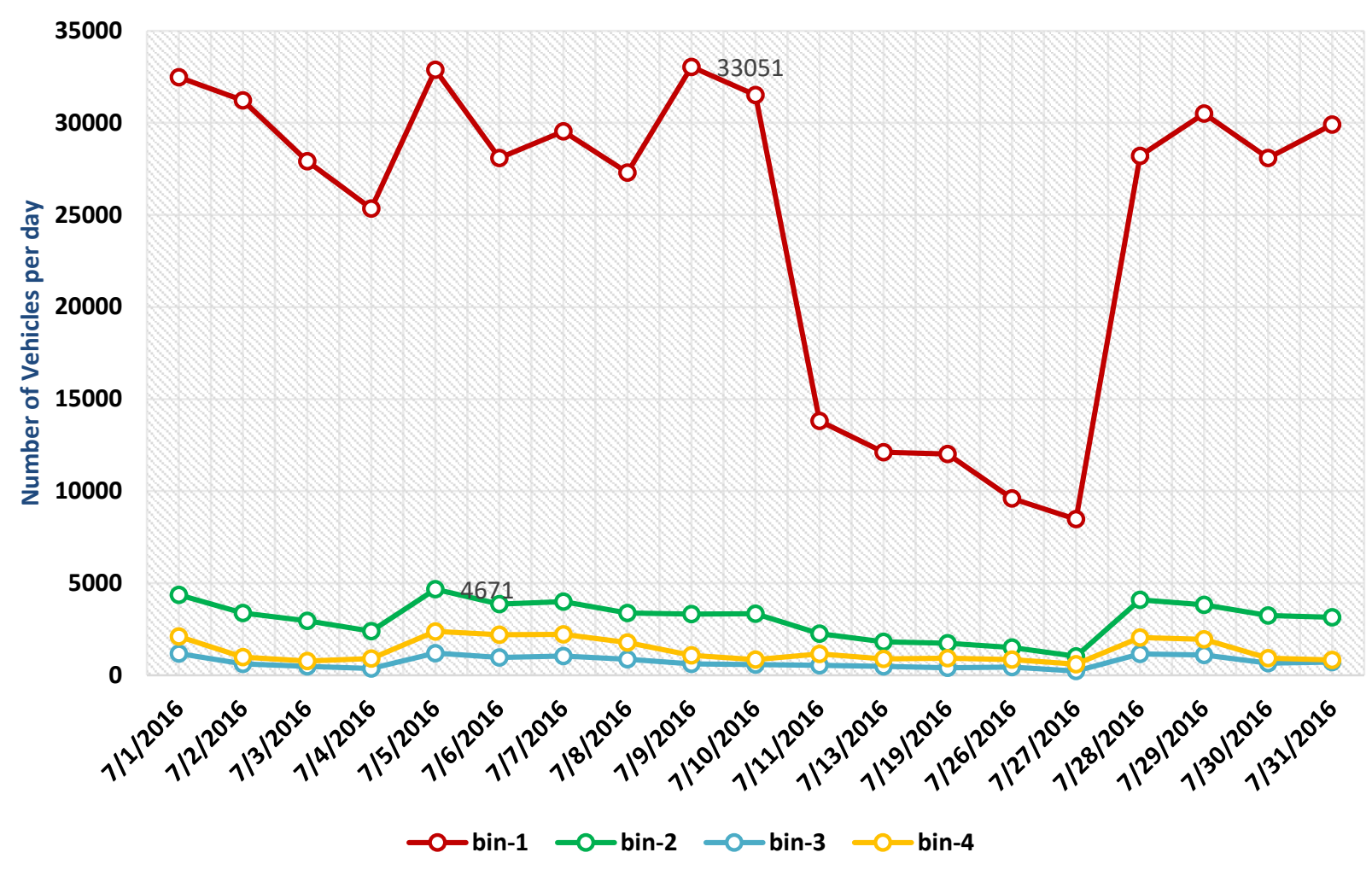

Figure 6: Station A, all categories mobility pattern for July 2016

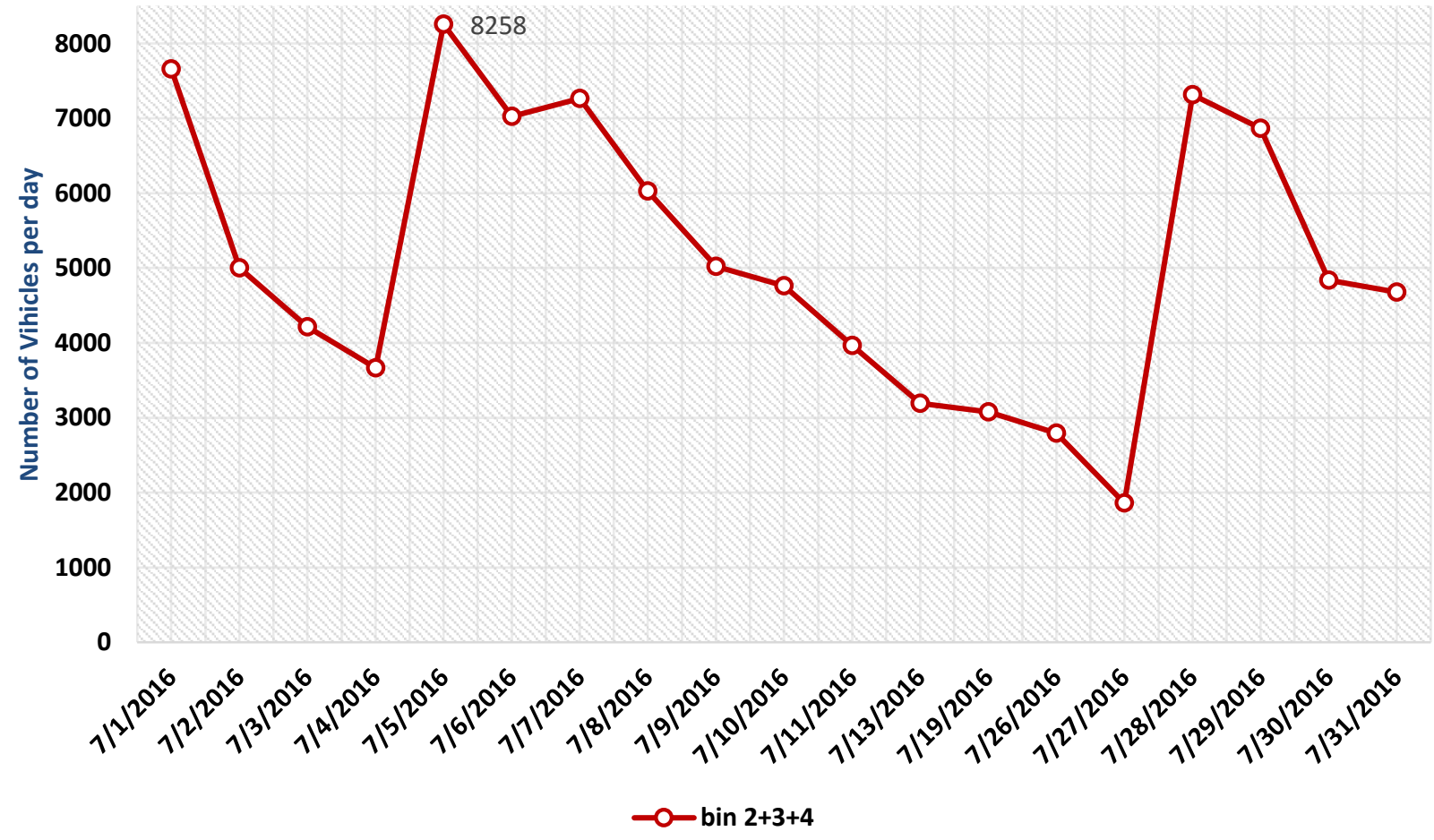

Figure 7: Station A Bin 2, 3 and 4 mobility pattern 
The disparities between bins 2, 3, and 4 have been clearly brought out by figure 8 below. There generally were longer bin 4 vehicles than the bin 3 category. The pattern throughout the month for both the freight categories was seemingly uniform as depicted by the curves.

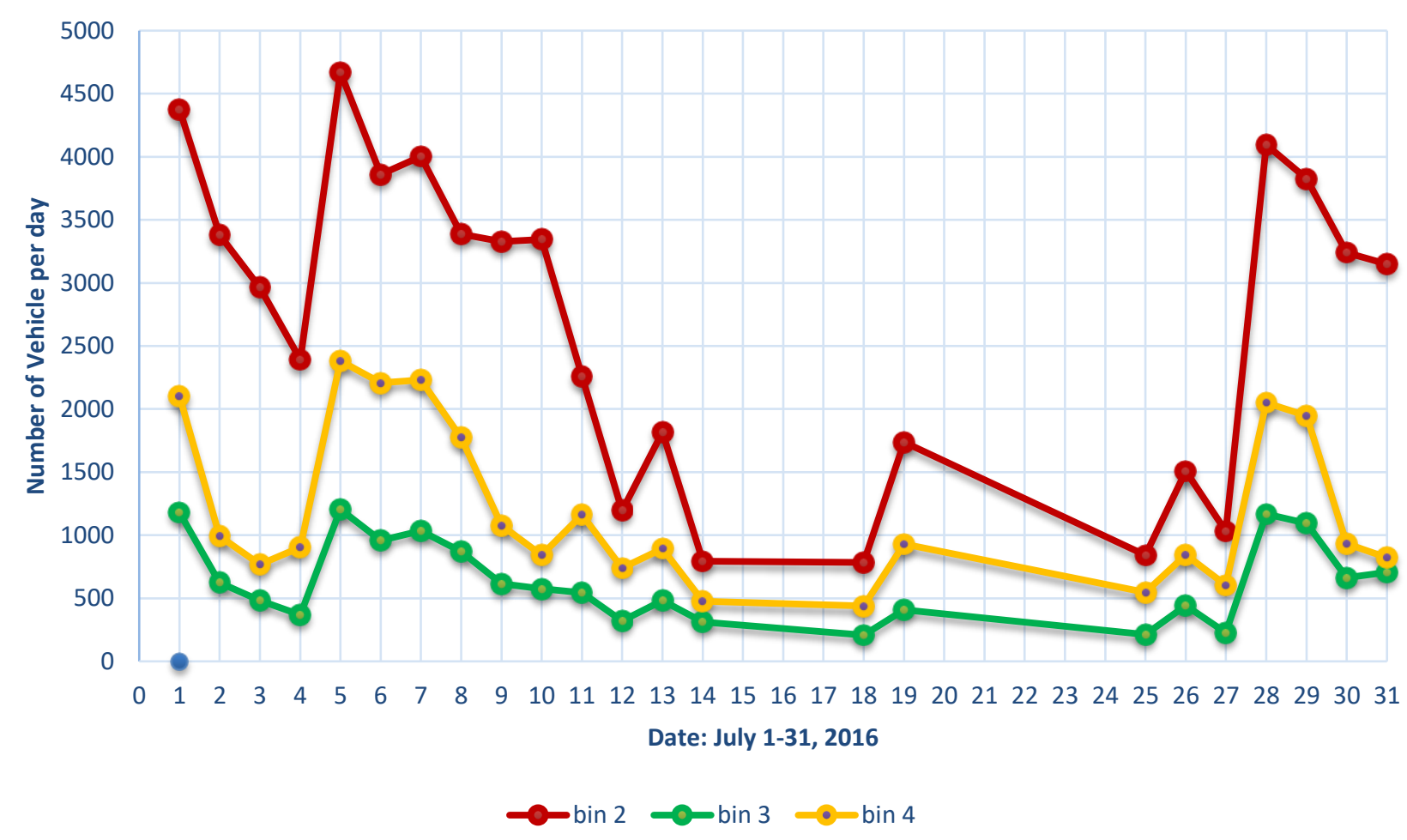

Figure 8: Station A Bin-2, 3, 4 Daily Counts

From the findings, the table below was used to bring out the percentage mobility of the freight trucks categories 2, 3, and 4 in comparison to the small vehicles (bin 1) categories.

Table 4: Percentage of Freight Analysis (Station A)

\begin{tabular}{|c|c|c|c|}
\hline & Bin 1 & Bin 2+3+4 & Total \\
\hline Counts & 472089 & 104346 & 576435 \\
\hline$\%$ & $82 \%$ & $18 \%$ & \\
\hline
\end{tabular}

Out of the total 576435 counted vehicles, in Station A, 104346 were the single unit trucks, long trailer and multi-trailer vehicle category. Whereas the small vehicle categories (bin 1) were 472089. The freight vehicles as trailers percentages were 18 per cent of the total vehicles counted. 


\subsubsection{Station A Freight Mobility Analysis Weekly Counts/Weekly Average}

Further to this, the trend for the vehicle categories was taken for a week and graphed (figure 9) below. Figure 10 and 11 shows the weekly and weekly average counts for bins 2, 3, 4 vehicles categories as observed from the counts. In relation to figure 9, the trend was similar except for the higher number of vehicles for the bin-1 category in Friday weekend days due to the July 2016 had 5 days of Friday, Saturday, and Sunday.

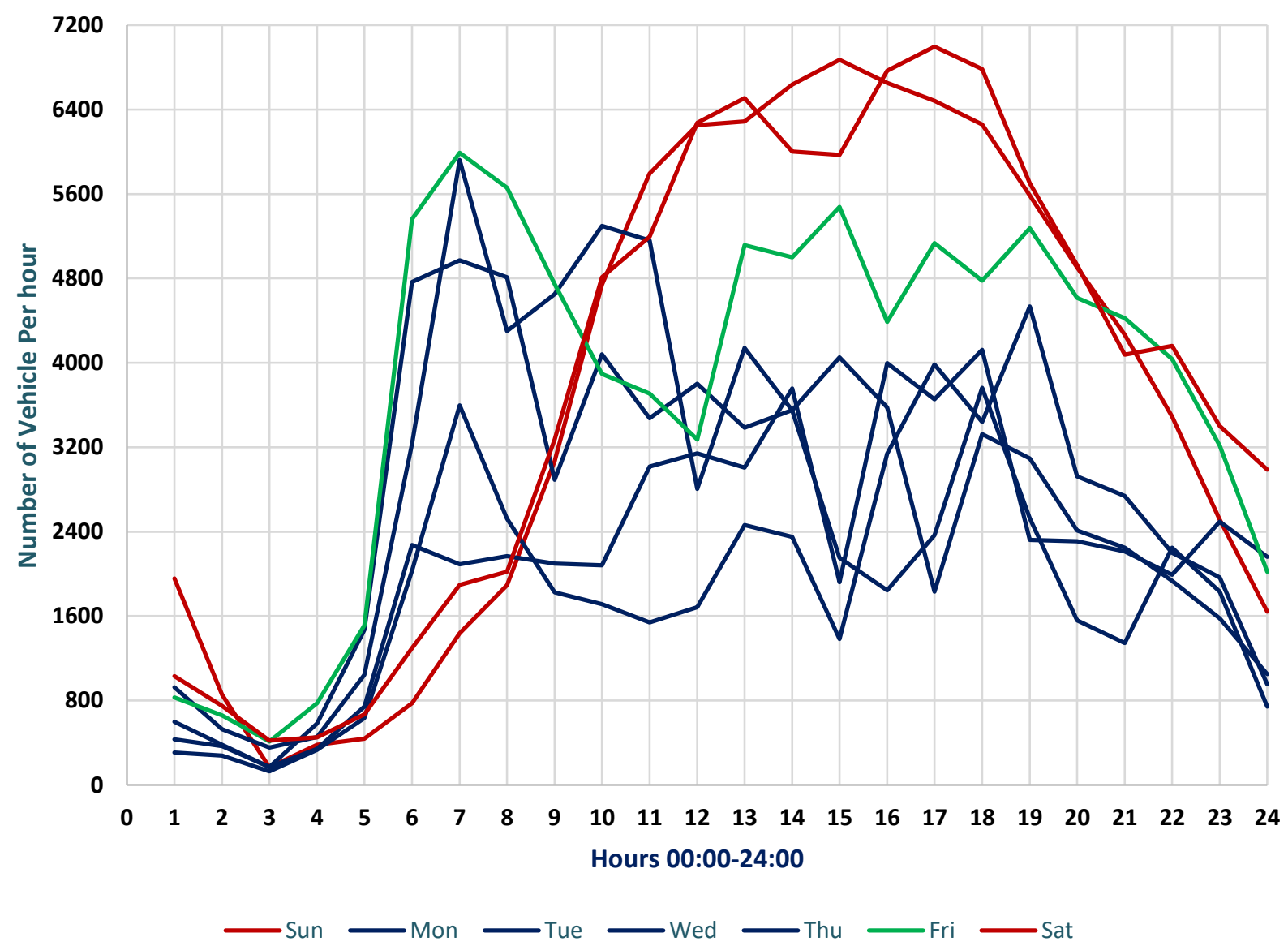

Figure 9: Station A, Bin-1 Weekly Counts July 2016 


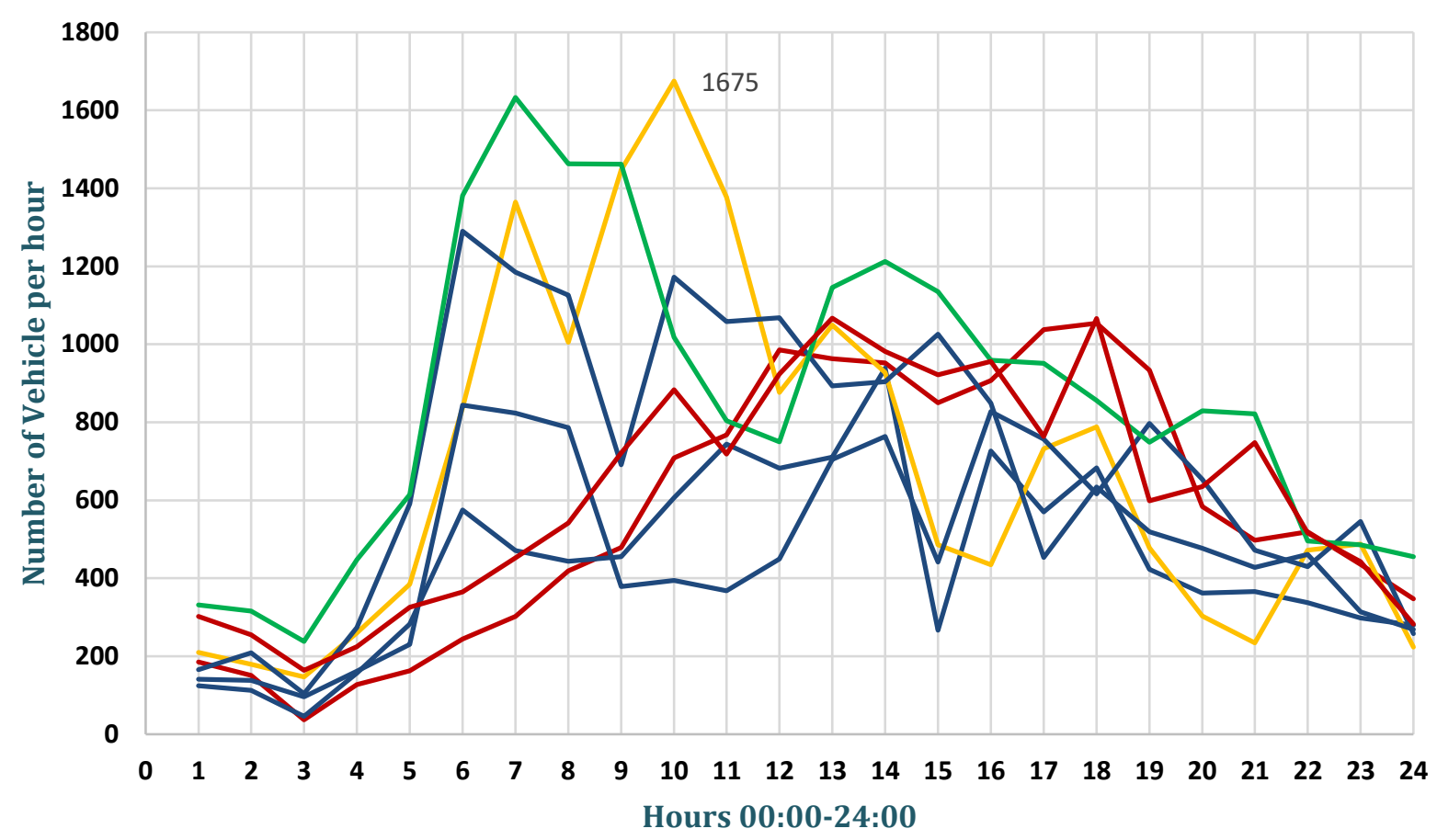

-Sun $\longrightarrow$ Mon Tue W Wed Thu Tri - Sat

Figure 10: Station A Bin 2, 3, 4 Weekly counts

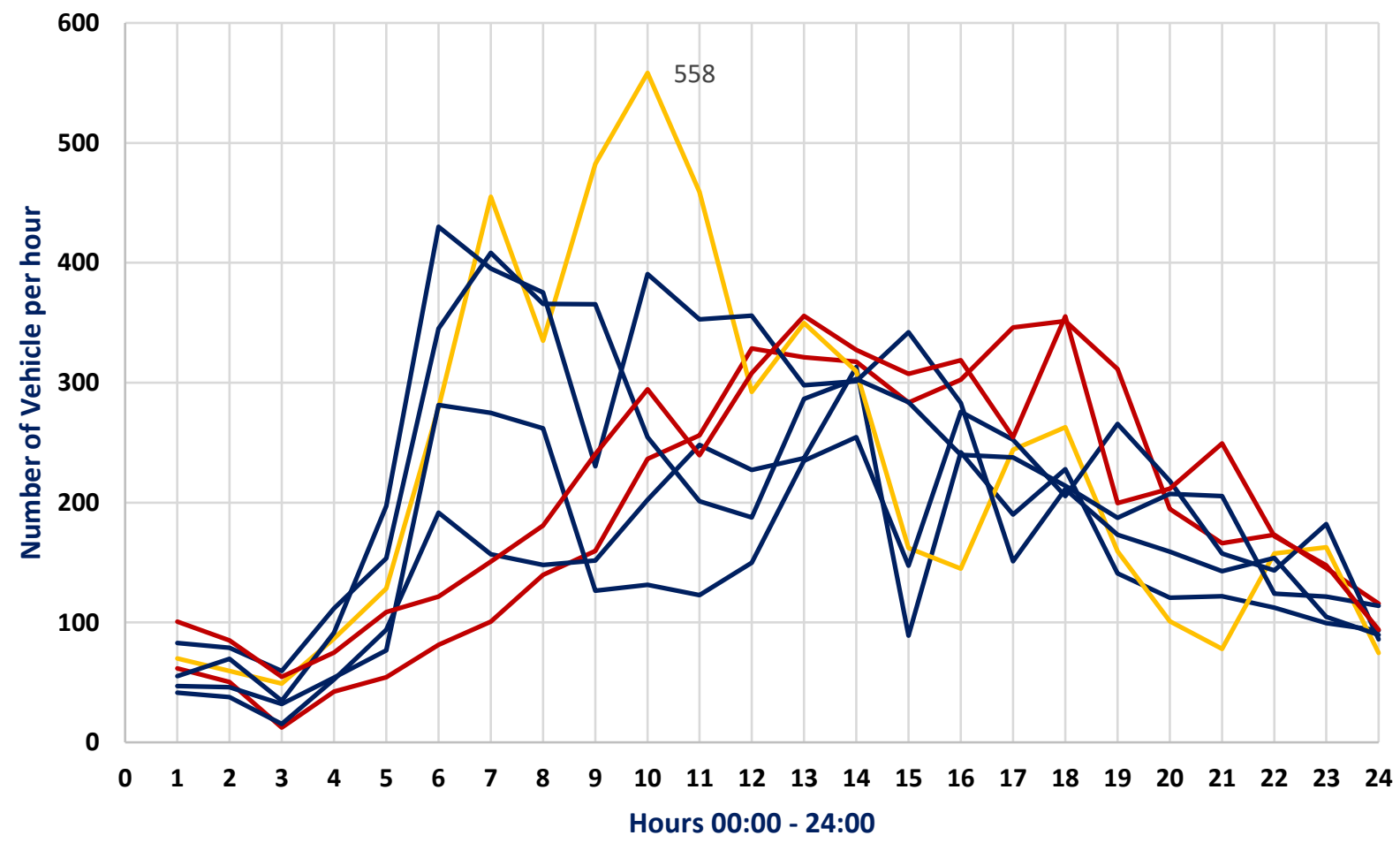

- Sun $\longrightarrow$ Mon $\longrightarrow$ Tue $\longrightarrow$ Wed $\longrightarrow$ Thu $\longrightarrow$ Fri $\longrightarrow$ Sat

Figure 11: Station A Bin 2, 3, 4 Weekly Average Counts 
During mid-day, the numbers of vehicles for passenger vehicles (bin 1) were higher than during end day and early days. Weekends saw a higher number of vehicles generally than weekdays. Comparatively, this was in contrast to the bin 2, 3, and 4 vehicle categories. On Sundays, the number of freight vehicles in Station A was comparatively lower than in other days. The numbers were higher during weekdays as depicted by figures 10 and 11 above. On the total weekly counts, Tuesday days, and on the average, Friday days, saw the highest trends of the freight categories (bin 2, 3, and 4) traversing Station A of Portland. This may be explained by the fact that most companies operate during weekdays than weekends. Freight movements between end points are definitely impacted by the working hour's patterns within Portland. In the mid of the day, there was a higher freight mobility than in the early of the days and the end of the day.

\subsubsection{Station A Freight Mobility Analysis (Work-Day)}

Further to the above, the mobility of freight vehicles during the weekday was analyzed and compared to the small vehicles category. There was similarity in the trend as illustrated by figures 12 and 13 except that there were more of bins 1 than freight vehicle categories. From the graphical trends illustrated below, there was high freight mobility during the middle of the day than in the early mornings and late days. This was probably because most of these long and freight vehicles transport goods over long distances. Overall, there was the highest percentage of freight vehicles (21 per cent) for the weekdays than for the weekends. The increased percentage was also true for vehicle 1 category as table 5 below illustrates.

\section{Table 5: Percentage of Vehicles for the Workdays}

\begin{tabular}{|c|c|c|c|}
\hline & Bin1 & Bin $2+3+4$ & Total \\
\hline Counts & 28203 & 7314 & 35517 \\
\hline$\%$ & $79 \%$ & $21 \%$ & \\
\hline
\end{tabular}

As explained in section 4.2.3 above, a relationship was derived between the freight mobility and normal working days. Most of the freight categories operate with the normal working schedule of Portland. The companies governing the freight mobility operate with this schedule too. This is the main probable cause for the high freight mobility during the normal working days than during the weekends as it will be seen in the succeeding sub-section. From the analyzed trend, there was the highest mobility peak for the freight vehicles in the middle of day than in the early 
and end and beginning of the day. The pattern as observed was in convergence with the bin 1 vehicle categories as seen in figure 12. This is depictive of stringent congestion scenarios at station A during these periods. It is evident from previous case studies that congestion greatly affects the smooth mobility of freight vehicles. This could be the main reason for the observed congestions in the mid-days of the working days since it is during the same times that there is peak traffic for the majority of the bin one vehicle categories.

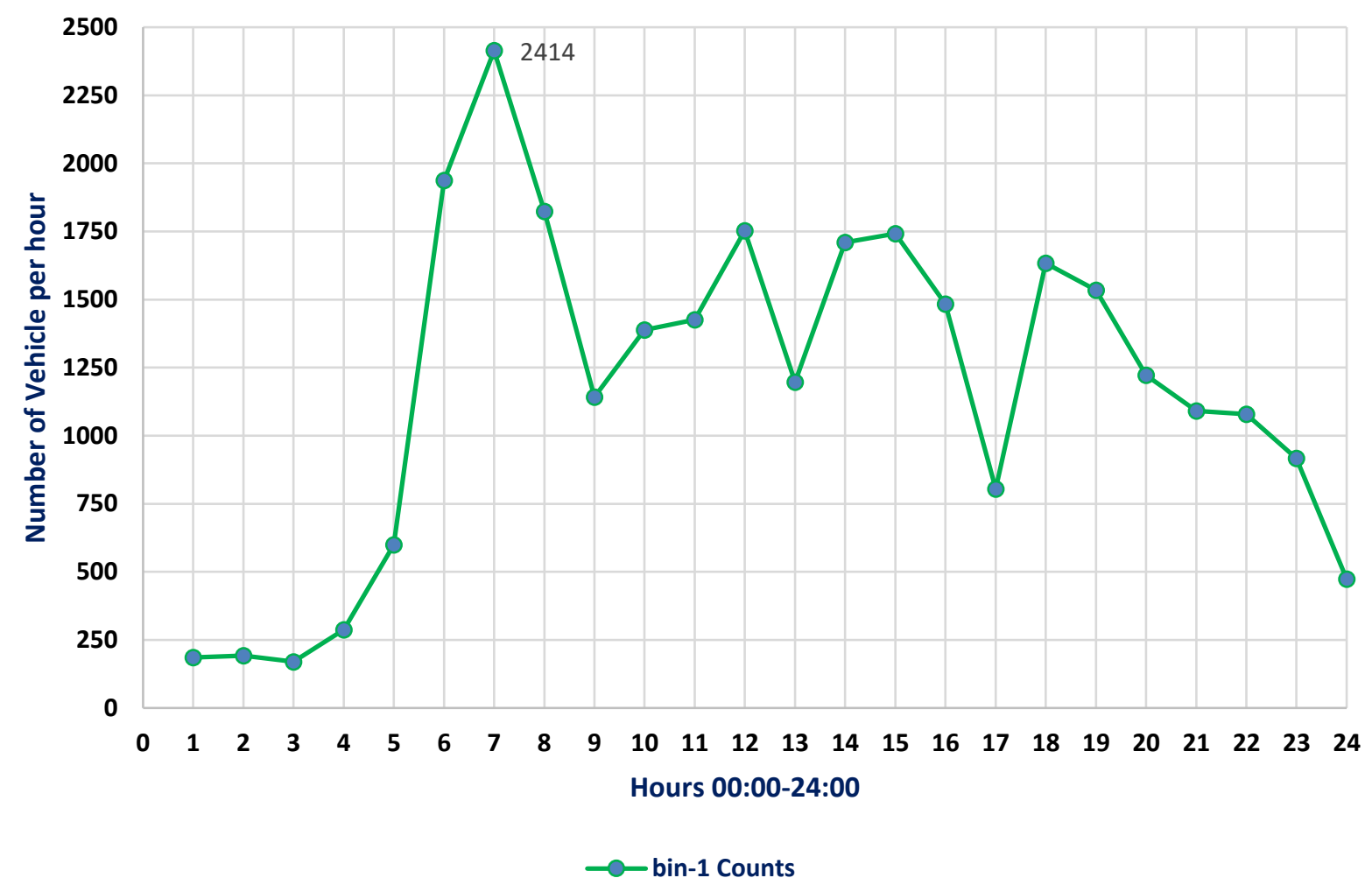

Figure 12: Station A Bin-1 Counts in Thursday, July $28^{\text {th }} 2016$ Workday 


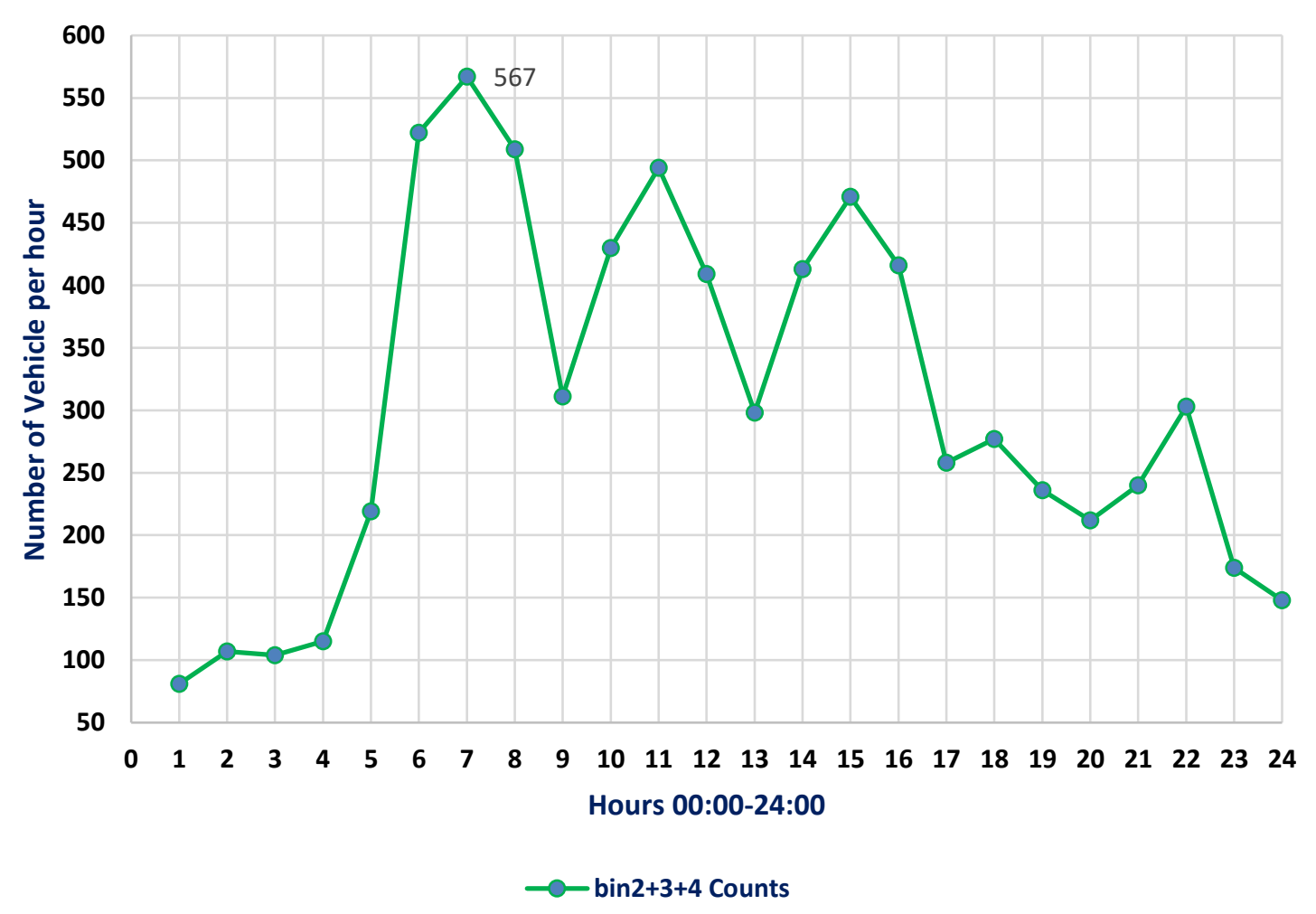

Figure 13: Station A Bin 2, 3, 4 Counts in Thursday, July $28^{\text {th }} 2016$ Workday

\subsubsection{Station A Freight Mobility Analysis Weekend Day}

Figures 14 and 15 below represent the derived counts for the bin 1 and combination of bin 2, 3, and 4 vehicle categories respectively for station A, but during the weekend day (Saturday). The average count was less during the weekends than during weekdays for the freight vehicle categories (bin 2, 3, and 4). Comparatively, this was true too for bin 1 category. Unlike bin 1, the freight vehicle categories bin 2,3, and 4's trend was so irregular with sharp rises and drops in the vehicle counts. The less number of freight mobility over the weekends could be explained by the fact that in the Portland, most companies do not open over the weekends since weekends are not considered to be working days. 


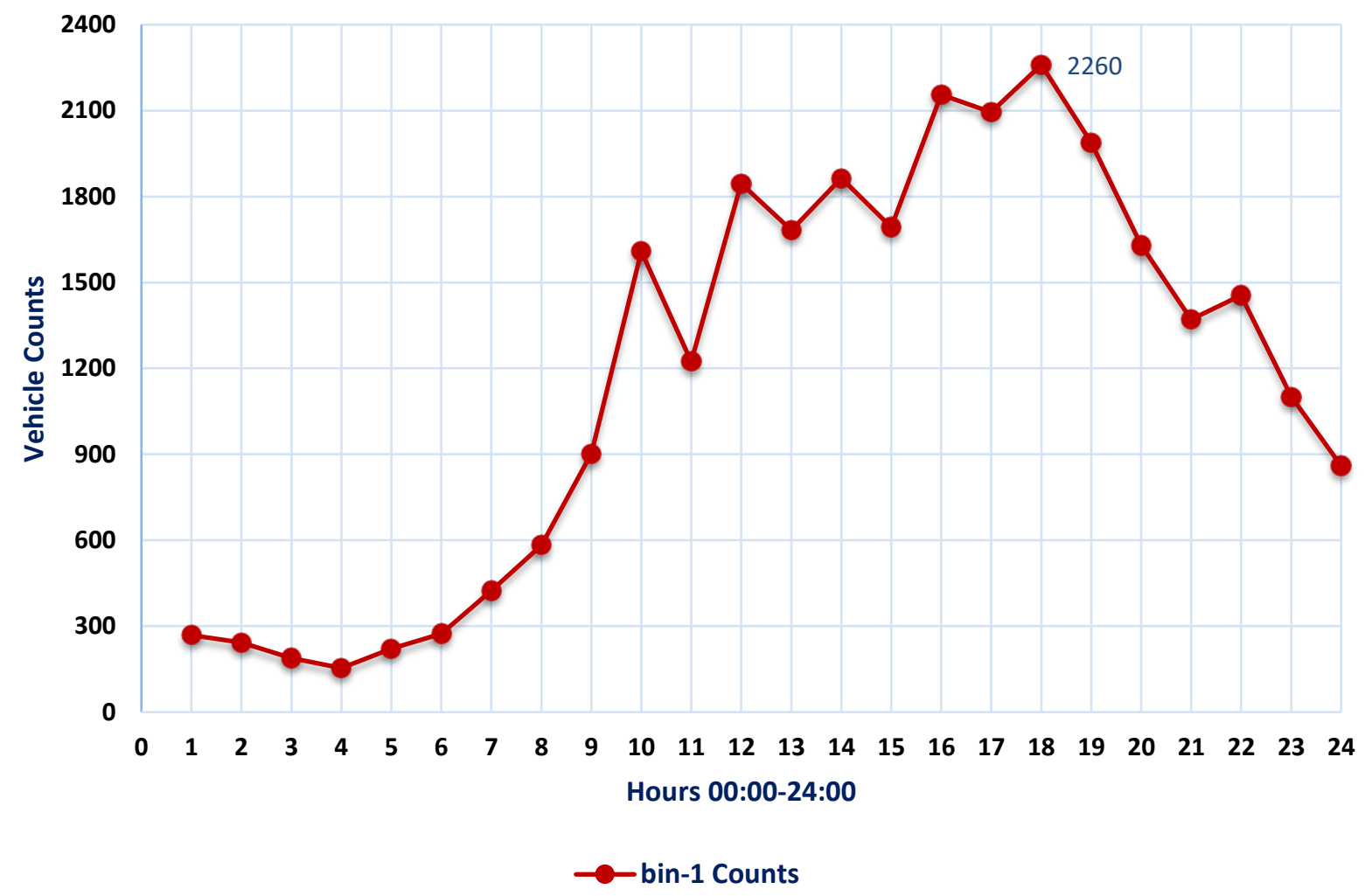

Figure 14: Station A Bin-1 Counts in Saturday, July $30^{\text {th }} 2016$ Weekend day

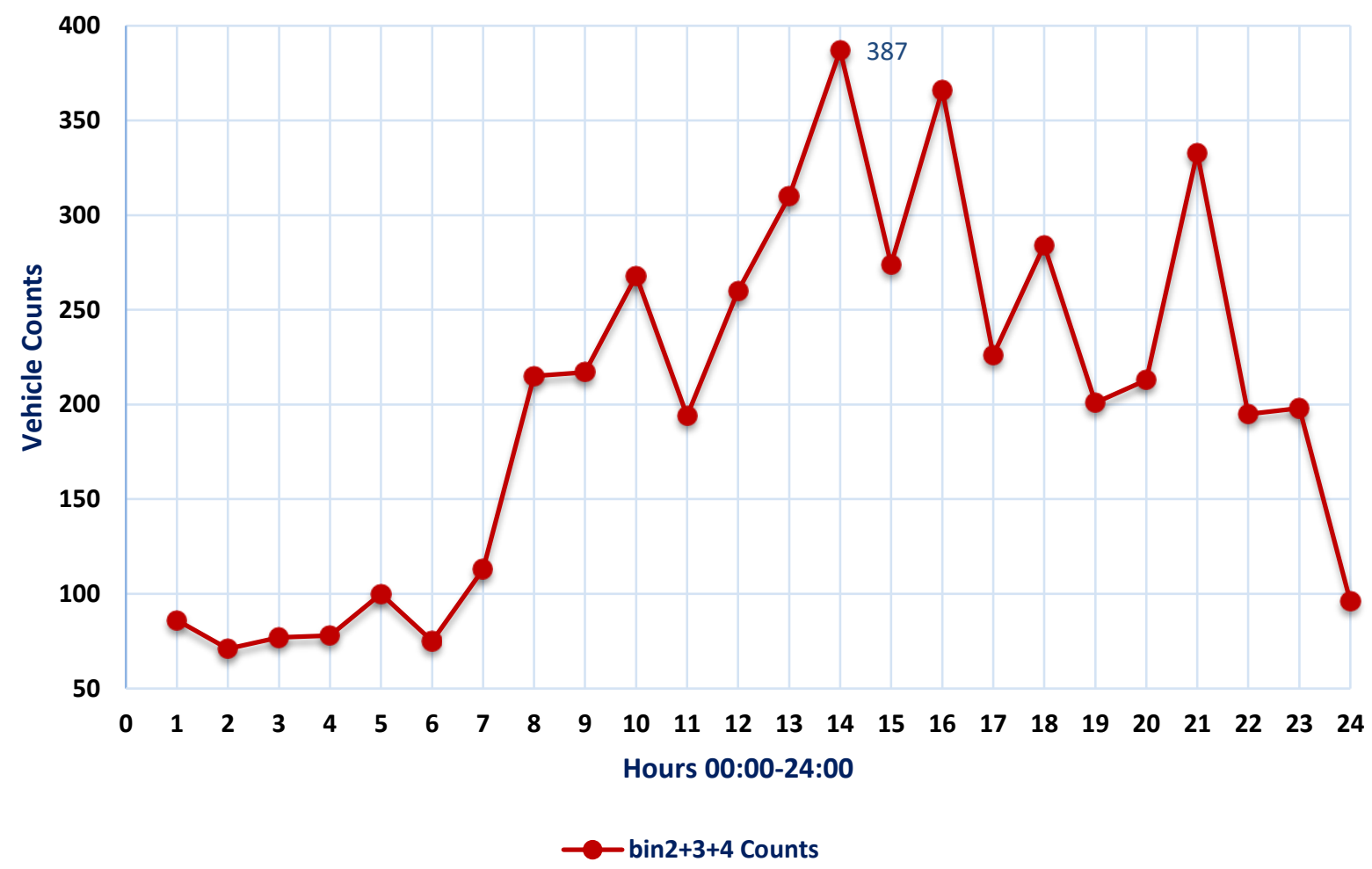

Figure 15: Station A Bin 2, 3, 4 Counts on Saturday, July 30 2016 Weekend day 
From table 6 , out of the 32,931 vehicles counted, this was a significant drop from the figure noted during weekdays. As for the freight and long vehicle categories, there were 4837 vehicles which were 15 per cent of the total number of vehicles counted. This too was a disparity from the 21 per cent count evidenced during the Thursdays of the same month. The main reason for the low freight mobility during the weekends was from the fact that most of the companies operating freight and logistic transactions were dis-functional during the weekends but during weekdays only.

\section{Table 6: Percentage Vehicle Counts for the Weekend}

\begin{tabular}{|c|c|c|c|}
\hline & Bin1 & Bin 2+3+4 & Total \\
\hline Counts & 28094 & 4837 & 32931 \\
\hline$\%$ & $85 \%$ & $15 \%$ & \\
\hline
\end{tabular}

\subsection{Station B South of the Portland}

\subsubsection{Daily Freight Mobility Analysis Station B}

Similar analysis, just as was done for the north of the Portland (Station A), was also carried out in the south of Portland (Station B) at corridor 2. The Northern Corridor seemingly displayed different trends than the south of Portland. For instance, the monthly count trends for the freight and long vehicle categories; there were the highest counts in the early of the month and towards the end of the month. This trend was similar to the normal vehicle categories represented by figure 16 below. High traffic congestion is known to be one of the most notorious factors impacting on the freight mobility in most areas, north Portland notwithstanding. This could explain the reason for the similarity in the trends. The North of Portland is known as a route for most of the freight traffic traversing the interstate -5 interchange. This is the reason why, 
comparatively, there seemed to be a relatively higher concentration of freight mobility in the Northern of Portland than it was in station B.

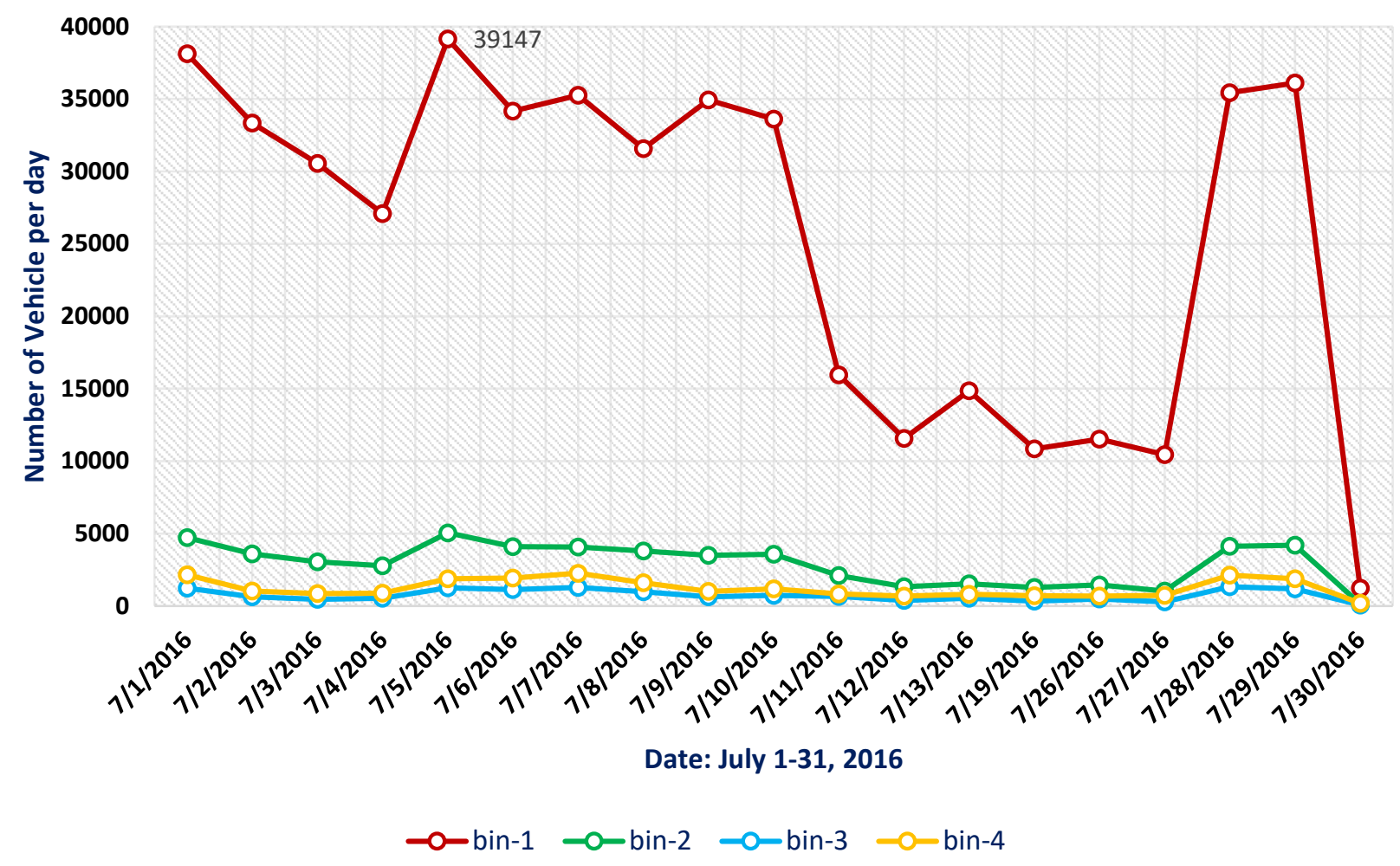

Figure 16: Station B, all categories mobility pattern 


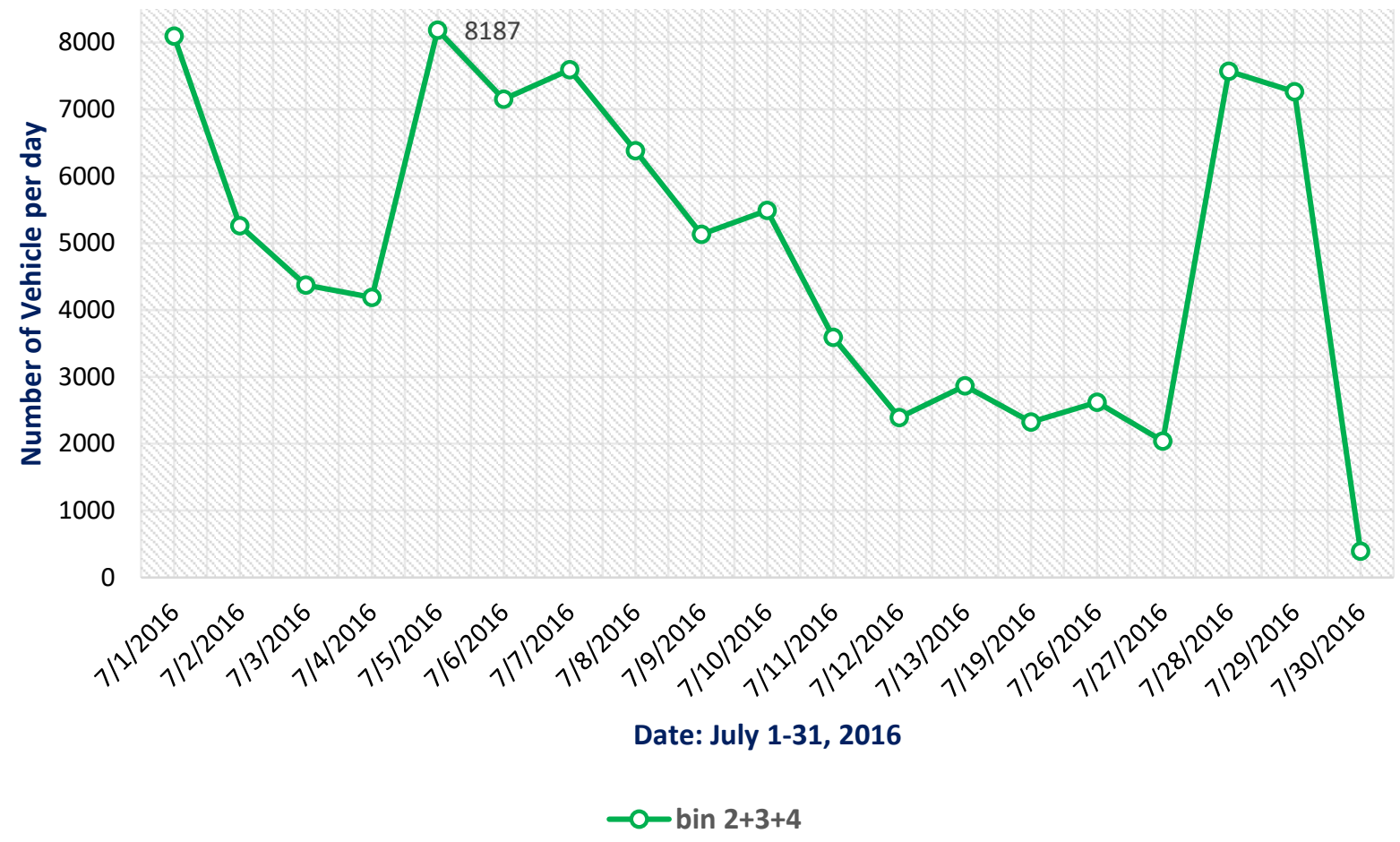

Figure 17: Station B, Bins 2, 3, 4 Categories mobility pattern

Out of the 563014 vehicles counted, 97763 were the freight and long vehicles. This represented 17 per cent of the vehicles as table 7 below shows. As explained earlier, traffic congestion caused by the bin- 1 vehicle categories significantly impacts on the freight mobility of any area. This was the case with the north of the Portland. Steep lanes are also a characteristic of the interstate 5 town of Portland. This too impacts on the ease of long vehicle and huge trucks movements. This reason also significantly impacts on the mobility ease for freight across the state.

Table 7: Percentage of Freight Daily Analysis (Station B)

\begin{tabular}{|c|c|c|c|}
\hline & Bin 1 & Bin 3+4 & Total \\
\hline Counts & 465251 & 97763 & 563014 \\
\hline$\%$ & $83 \%$ & $17 \%$ & \\
\hline
\end{tabular}




\subsubsection{Station B Freight Mobility Analysis Weekly Counts $\backslash$ Weekly Average}

Figures 18 and 19 give the comparison basis for the weekly vehicle count in a bid to better understand the trends depicted by the freight and long vehicle categories (figures 20 and 21). There was generally higher number of freight vehicles durinig weekdays than during the weekends as the graphs show. Sundays and Saturdays showed relatively lesser bin 2, 3, and 4 counts. This is true from the weekly counts and weekly averages computed. It is also true that there was higher freight mobility during the mid days and less of this in the beginning and towards the end of the day. The freight mobility trend picked on a similar pattern as the bin 1 vehicle category trend except that on average, bin 1 vehicle categories had a higher count over the weekends. Freight movement during the weekends is limited by the fact that most companies close on Fridays and resume on Mondays as the tradition is in Portland. This trend was also true for Station A.

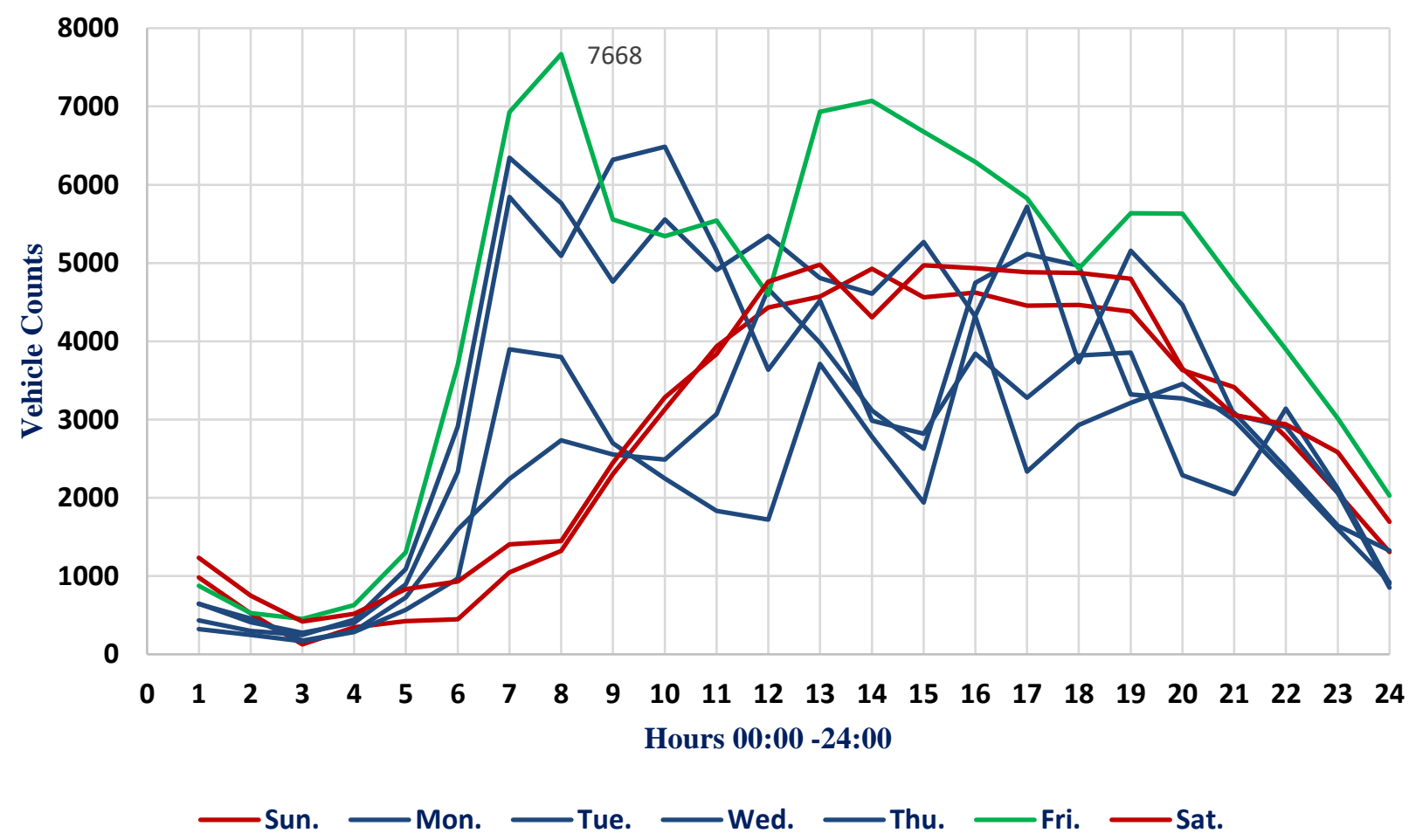

Figure 18: Station B, bin-1 Weekly Counts 


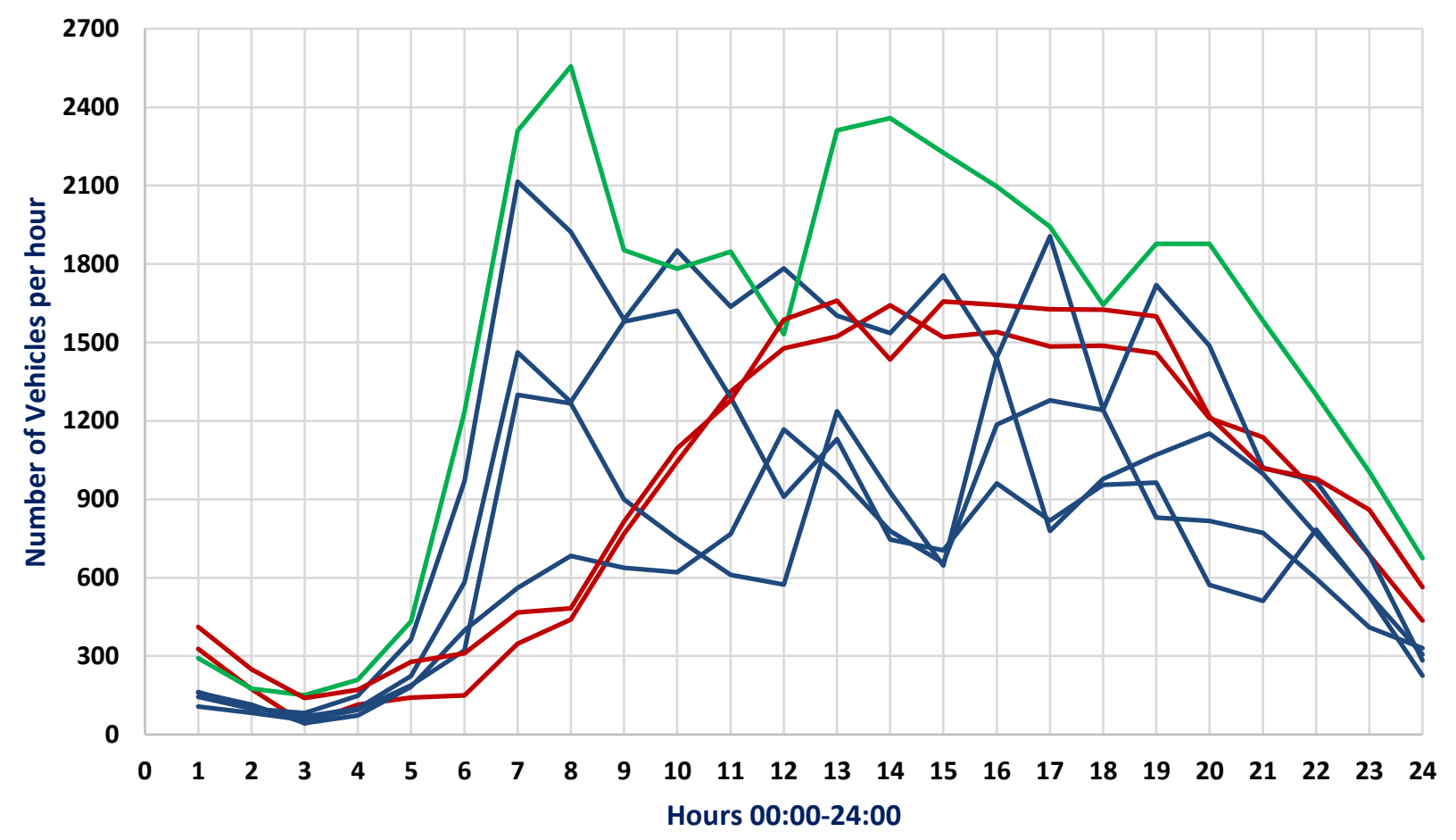

Sun - Mon -Tue Wed Thu Wri Sat

Figure 19: Station B, bin 1 Weekly Average Counts

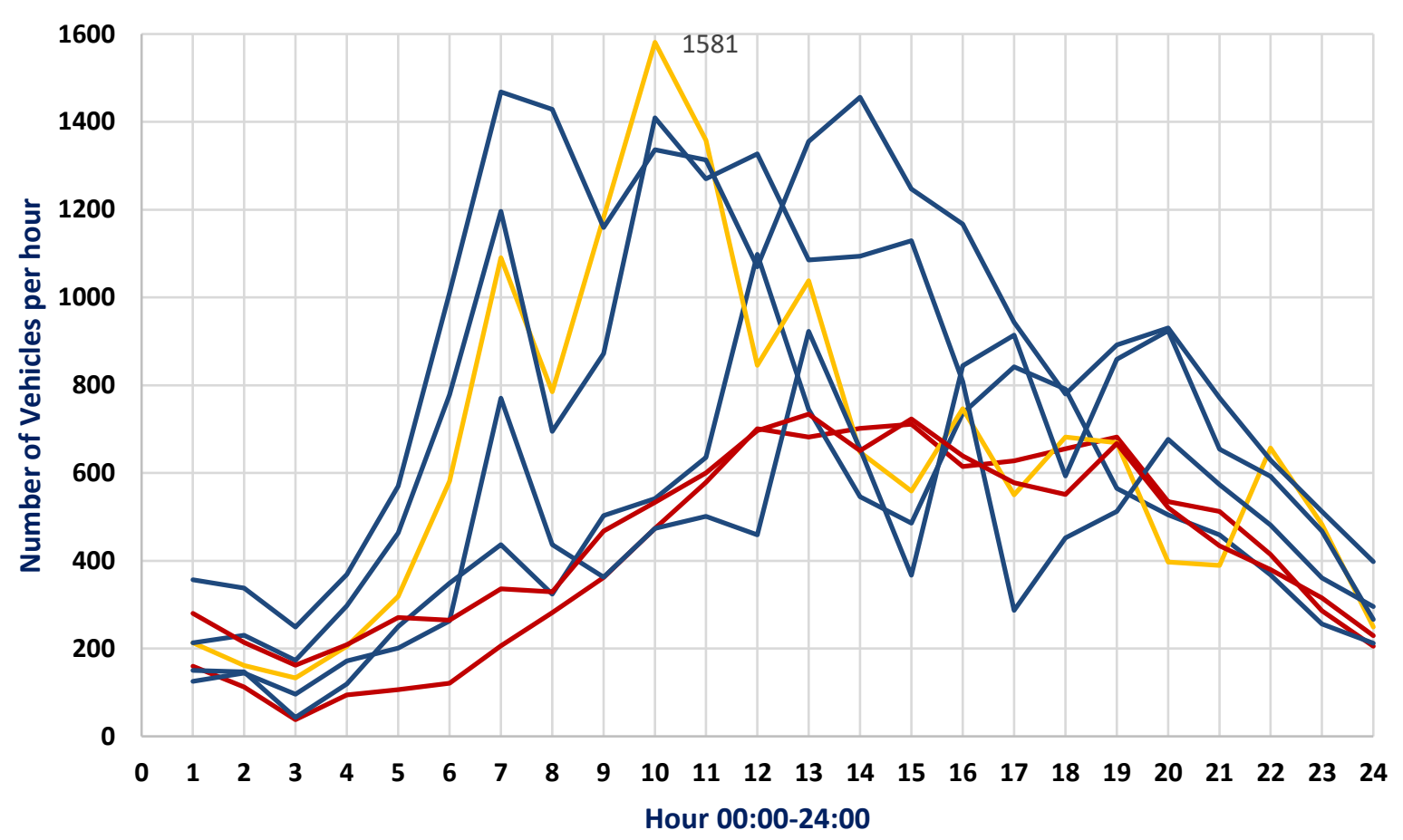

Cun $\longrightarrow$ Mon $\longrightarrow$ Tue Wed Thu Tri $\longrightarrow$ Sat

Figure 20: Station B, bins 2, 3, 4 Weekly Counts 


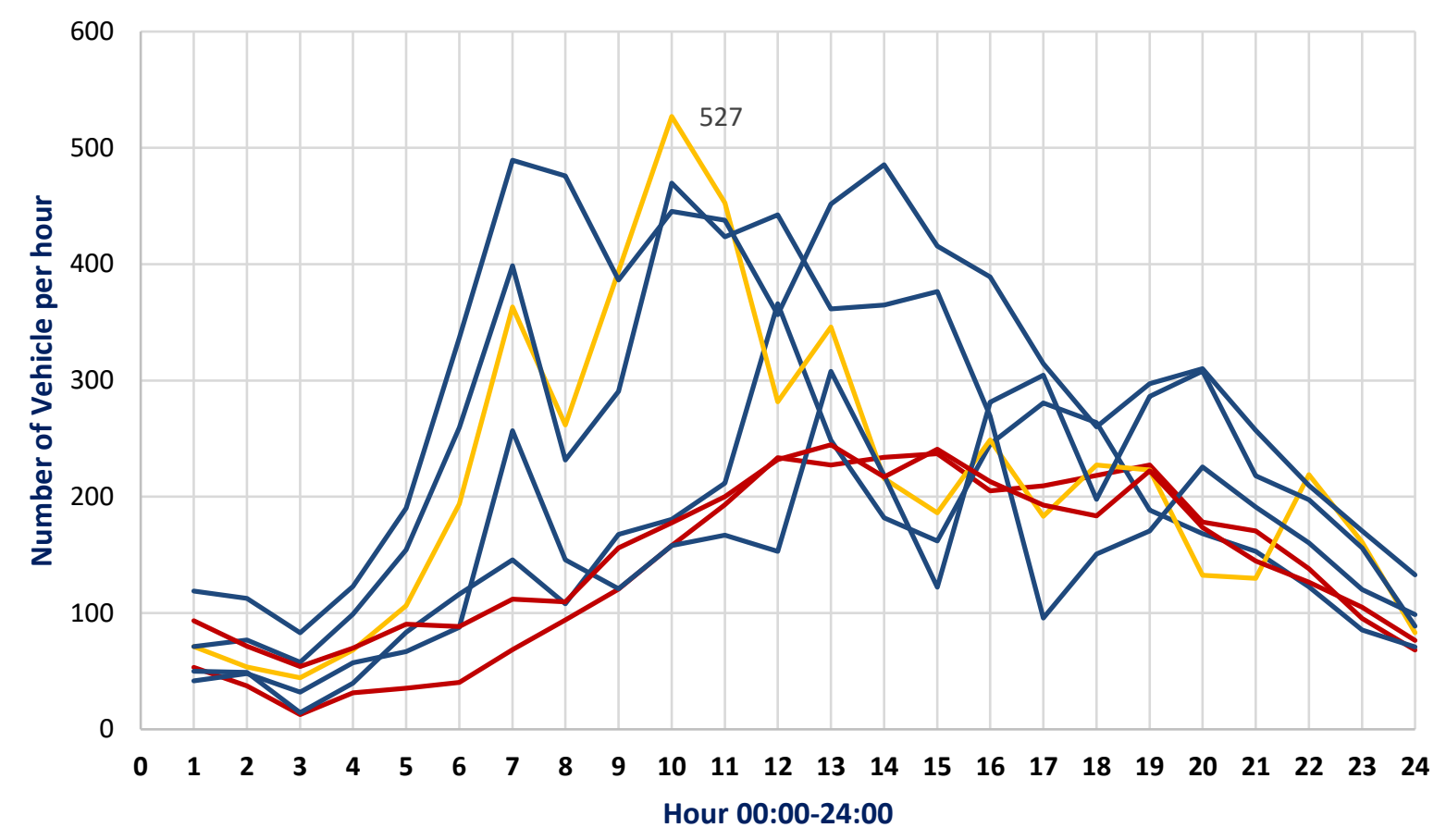

-Sun - Mon -Tue Whed Thu - Fri - Sat

Figure 21: Station B, bins 2, 3, 4 Weekly Average Counts

\subsubsection{Freight Mobility Analysis Station B (Work-Day)}

During the working days, the bin 2, 3, and 4 counts were highest in the mid-days than in the beginning of the days. There was higher freight mobility during the working days than during the weekends in the North of Portland. Bin 1 counts were also highest during these times giving the pictorial forecasting of traffic congestions during these periods which consequently impacts on the ease of freight mobility. These trends are well explained by the figures 22 and 23 below. It is during working days that most companies transact business and transport goods and services hence the trend. As table 8 below shows, out of the counted 47334 vehicles during the working days (Tuesdays), 8187 were trucks and long vehicles (bin 2, 3, and 4). This represented 17 per cent of the total count. Bin 1 had of course, the highest count with 83 per cent. 


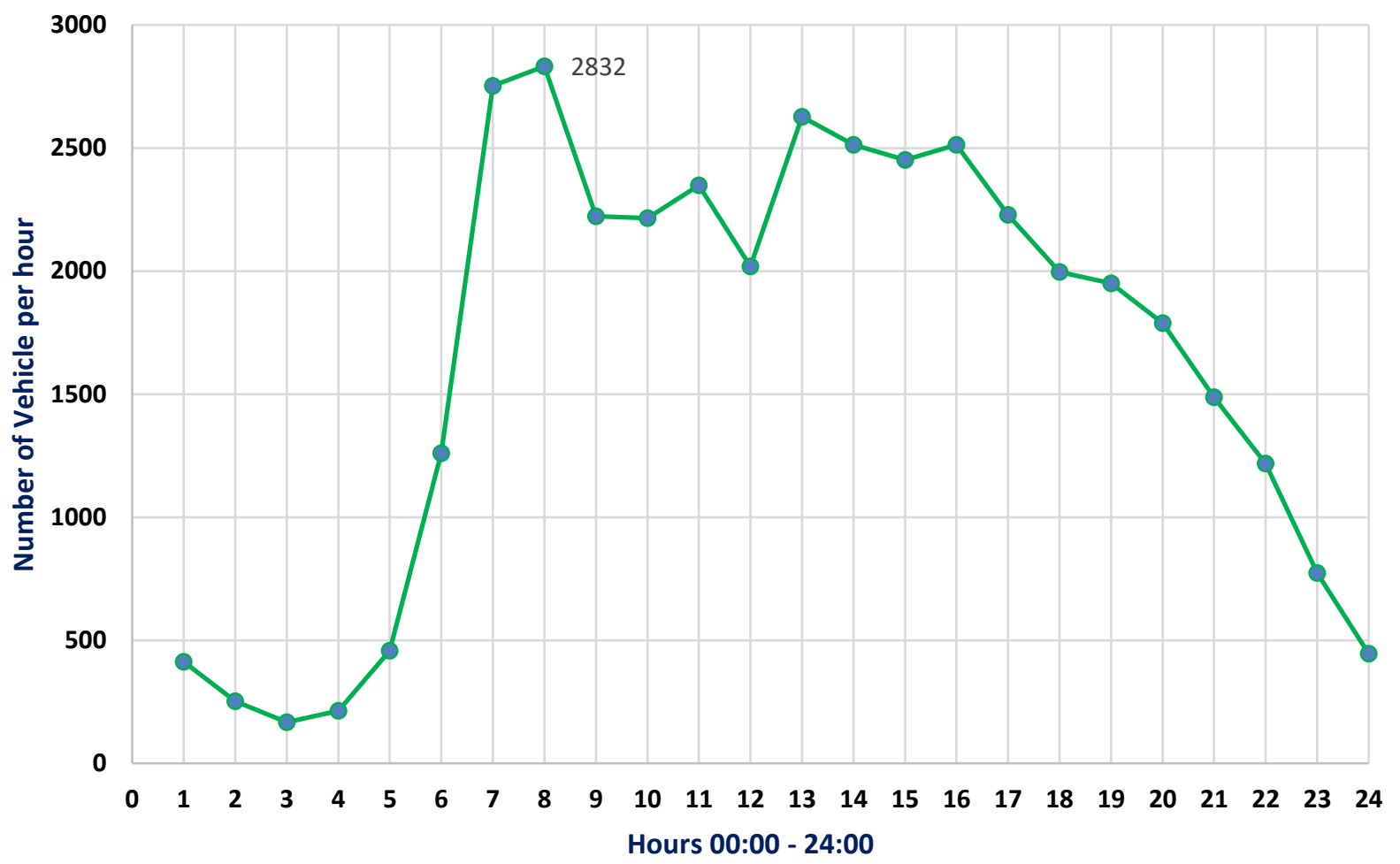

$$
\multimap \text { bin-1 }
$$

Figure 22: Station B, Bin-1 Counts in Tuesday, July $5^{\text {th }} 2016$ Work day

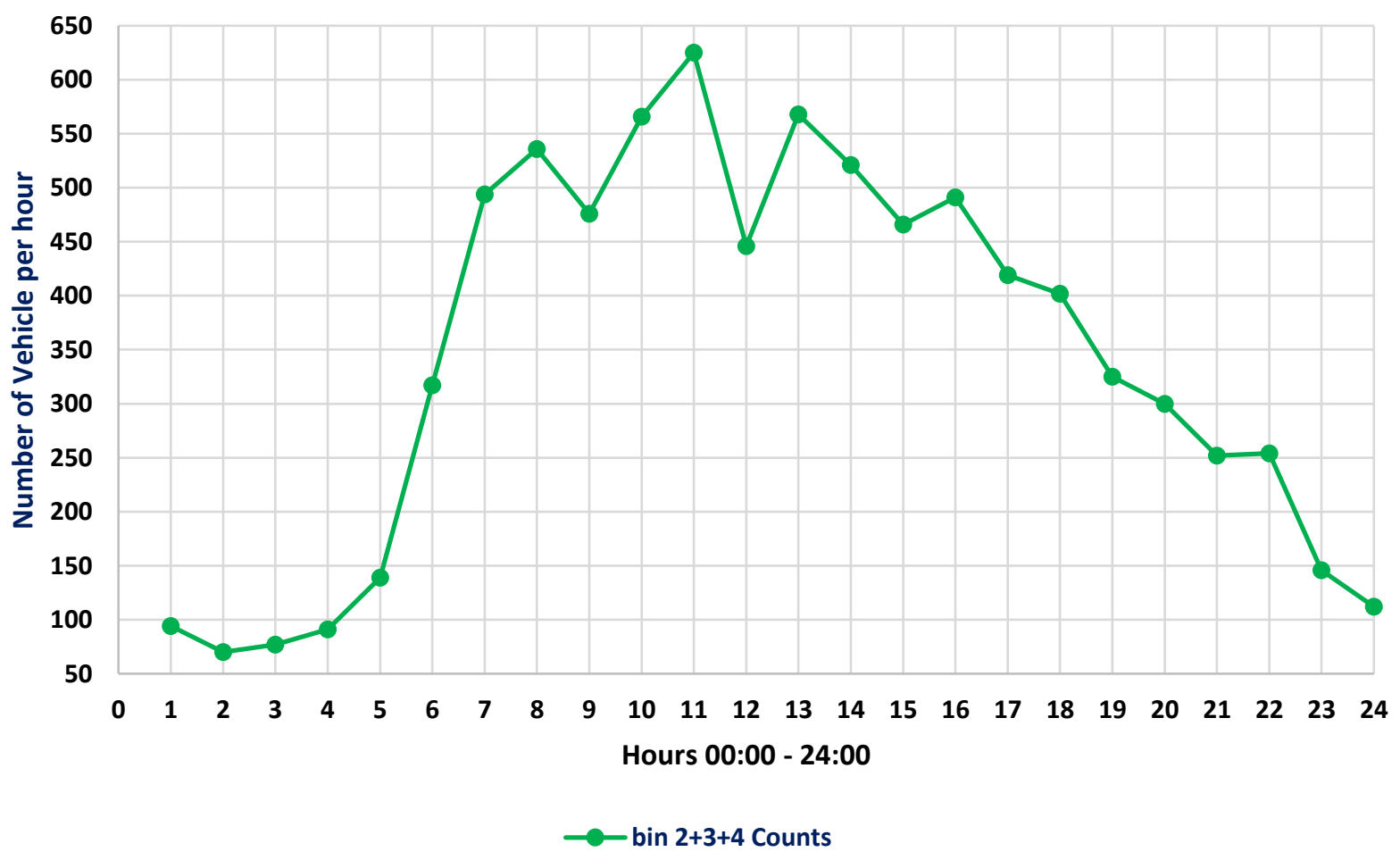

Figure 23: Station B, Bins 2, 3, 4 Counts in Tuesday, July $5^{\text {th }} 2016$ Work day

31 
Table 8: Working Day Percentage Analysis for Station B

\begin{tabular}{|c|c|c|c|}
\hline & Bin 1 & Bin 2+3+4 & \\
\hline Counts & 39147 & 8187 & 47334 \\
\hline$\%$ & $83 \%$ & $17 \%$ & \\
\hline
\end{tabular}

\subsubsection{Freight Mobility Analysis for Station B, Weekend day}

Figures 24 and 25 show the mobility of bin- 1 and bin2, 3, and 4 respectively on a weekend day (Saturday). In general, there were less vehicles during the weekend relative to the weekday (discussed above). There was a sharp rise/drop pattern for the freight and long vehicle categories during the weekend when compared to the non-freight vehicles categories, represented by bin. Generally however, there were a rising number of freight vehicles with the peak occurring during mid-day and a sink during very early mornings and very late evenings. From table 9, out of the counted 40000 vehicles, only 5068 happened to be the freight and long vehicle categories. The non-freight category represented 87 per cent of the total.

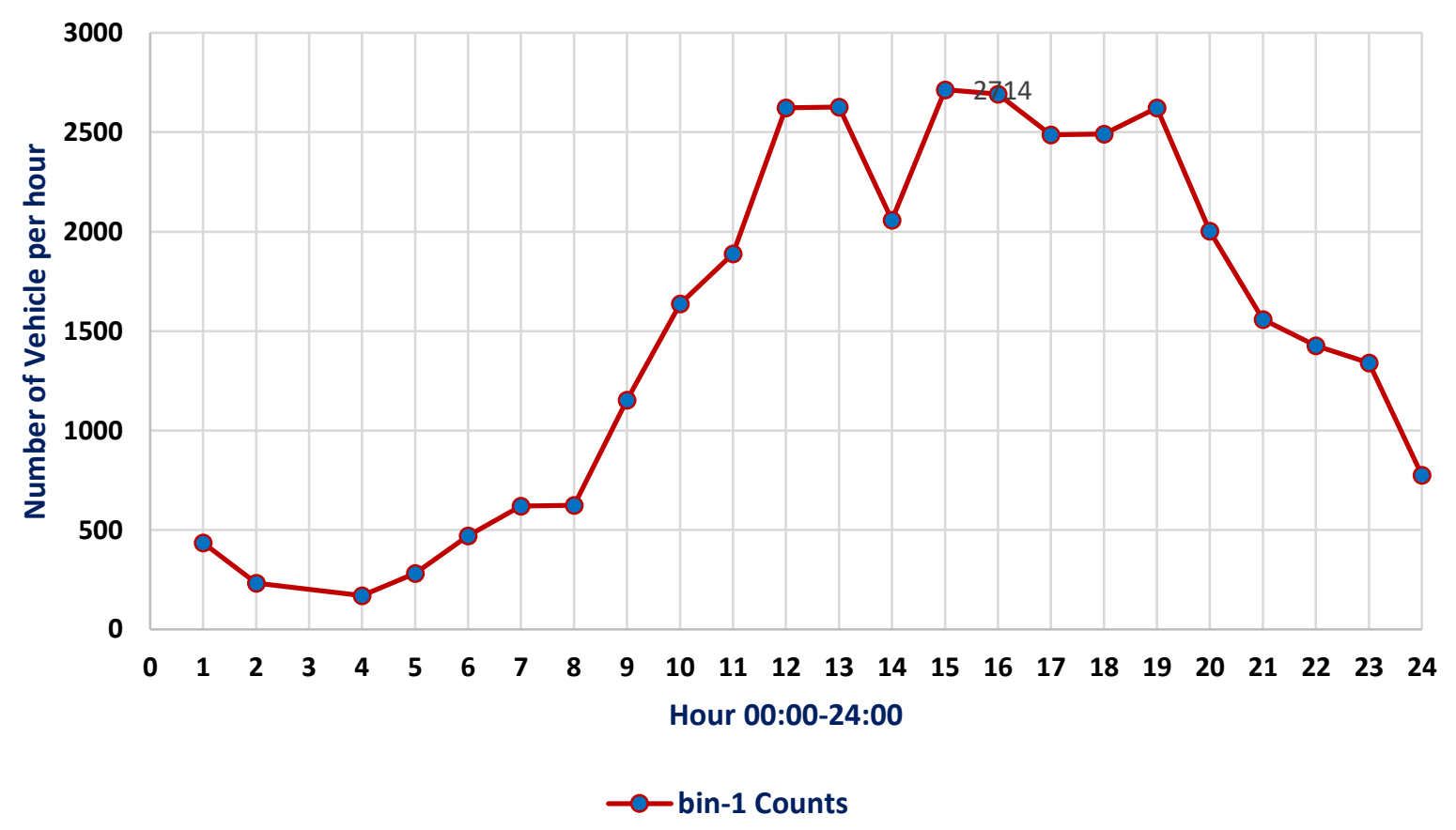

Figure 24: Station B, Bin-1 Counts in Saturday, July $9^{\text {th }} 2016$ Weekend day 


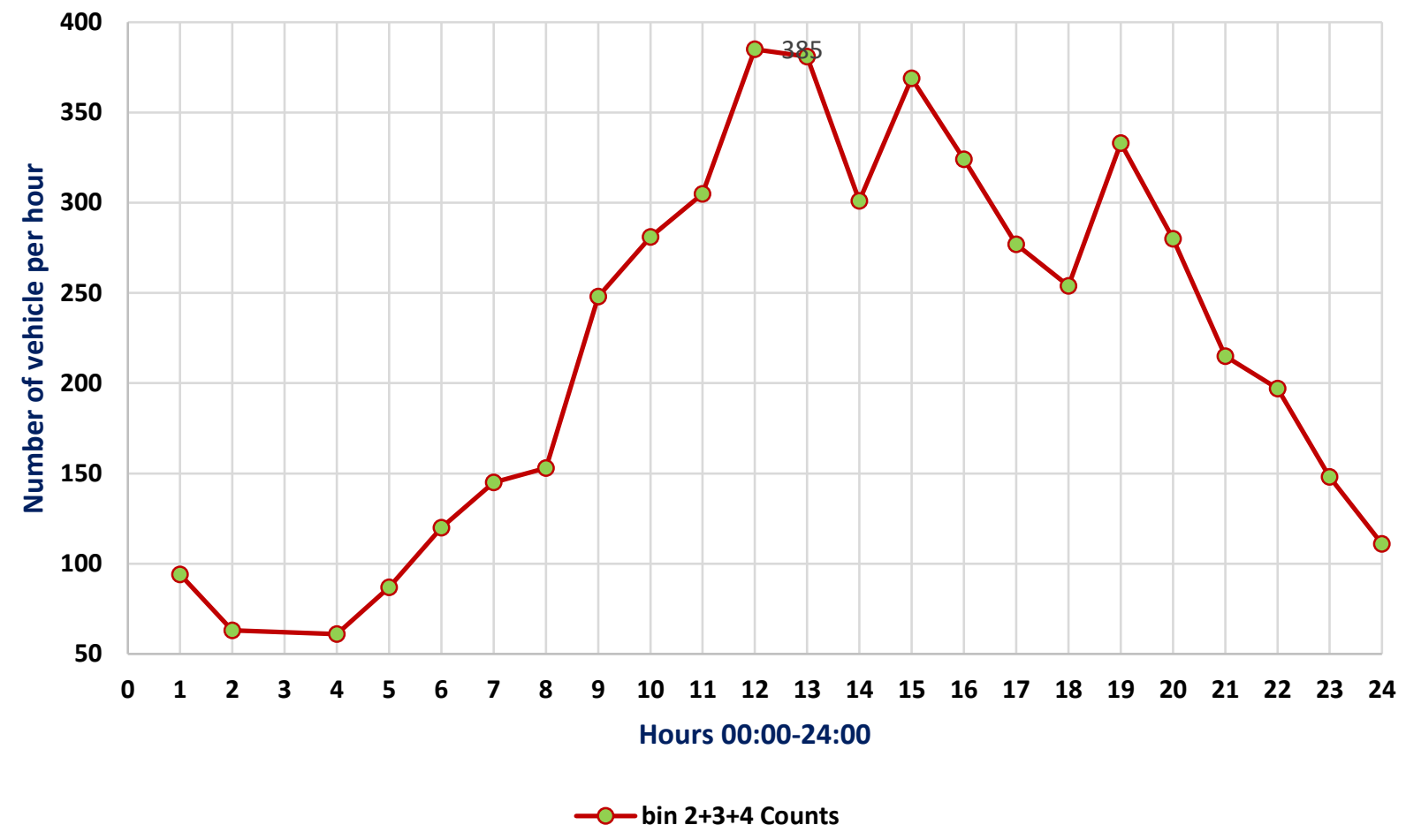

Figure 25: Station B, Bins 2, 3, 4 Counts in Saturday, July $9^{\text {th }} 2016$ Weekend day Table 9: Freight Mobility Percentage Analysis for Station B - Weekend

\begin{tabular}{|c|c|c|c|}
\hline & Bin 1 & Bin 2+3+4 & \\
\hline Counts & 34932 & 5068 & 40000 \\
\hline$\%$ & $87 \%$ & $13 \%$ & \\
\hline
\end{tabular}

\subsection{Trade Off between Station A and B}

Figure 26 below show the combination of bin 2, 3, and 4 counts in the whole month of July 2016 for both stations A and B. The pattern throughout the month for both of the freight categories was seemingly uniform as depicted by the curves, except in some days in the beginning of the month the total counts for freight mobility in Station A is higher than the total counts in station B. However, in fewer days in the mid of the month the counts of station A sink below the counts of station B. Table 10 below shows the total counts for bin 2, 3, and 4 for both stations and the percentage of the freight categories in both stations, whereas the total counts for freight categories in Station A is higher than in station B, the percentage of freight mobility in station A is $20 \%$ over total counts, while in station B the percentage of freight vehicles is $18 \%$. This assures that the freight movement in the north of the Portland city is higher a little bit than in the south of Portland. 
Table 10: Trade-off between Station A and B

\begin{tabular}{|c|c|c|}
\hline & Bin 2+3+4 Counts & \% for Total \\
\hline Station A & 104346 & $\mathbf{2 0 \%}$ \\
\hline Station B & 97763 & $\mathbf{1 8 \%}$ \\
\hline
\end{tabular}

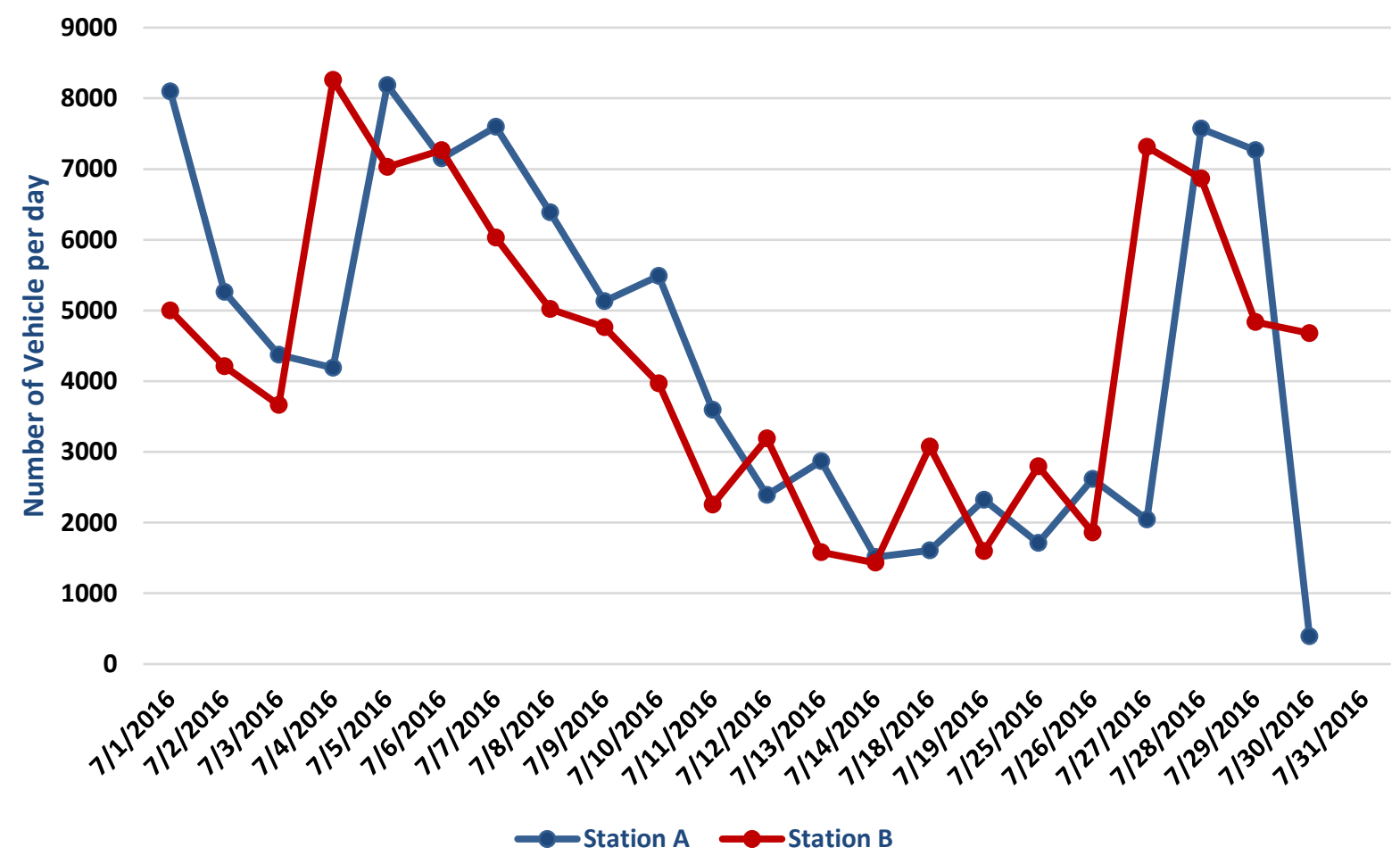

Figure 26: Trade-off between Station A and B, Combination of Bins 2, 3, 4 Counts

\subsection{Freight Mobility Percentage Analysis}

From the two groups of stations in the north and south of the Portland region have been picked in the data used for this research, six stations were picked too, three from each group for percentage analysis. Station 170, 180, and 185 in the north of the city, whereas Station 83, 157, and 355 in the south of the city of Portland; have picked and average percentage calculated for all the vehicle categories and the results illustrated in table 11 below. 
Table 11: Percentage Freight Analysis - Group of Stations Average

\begin{tabular}{|c|c|c|c|c|c|}
\cline { 2 - 5 } \multicolumn{1}{c|}{} & \multicolumn{4}{c|}{ Average Trucks Percentage } & \multirow{2}{*}{} \\
\cline { 2 - 5 } \multicolumn{1}{c|}{} & Stations & Bin-1 & Bin 2+3+4 & Total & ODOT \% \\
\hline $\begin{array}{c}\text { Group } \\
\text { (North) }\end{array}$ & $\begin{array}{c}170,180, \\
185\end{array}$ & 391060 & 109357 & 500417 & \multirow{2}{*}{$\mathbf{7 2 \%}$} \\
\cline { 1 - 5 } $\begin{array}{c}\text { Group } \\
\text { (South) }\end{array}$ & $\begin{array}{c}83,157, \\
355\end{array}$ & 405339 & $\mathbf{2 2 \%}$ & & \\
\cline { 3 - 6 } & & $\mathbf{7 9 \%}$ & $\mathbf{2 1 \%}$ & & \multirow{2}{*}{$\mathbf{2 4 \%}$} \\
\hline
\end{tabular}

The results showing that bin 2, 3, and 4 vehicle categories which are mostly wide and loaded from traversing the North Stations had the higher percentage than in the South albeit the minute disparity (i.e. 22 against 21 per cent respectively). Bin 1 category of vehicles had similar differences of percentage of other categories in both the stations as well. Mostly, the freight vehicle categories traverse both groups of the stations while going out of Portland. It is therefore possible that the respective vehicles that were captured and analyzed were similar hence the synonymy in percentage. This is in contrast with the bin-1 category. It is possible that mostly out of the driving population; they travel for shorter distances to and from their work places.

Comparatively, these percentages of the analysis the stations here, with the truck rates from ODOT- Traffic monitoring page for both regions; are agreeing with the north stations percentage average (22\%). Whereas the average percentage in the South stations is $21 \%$, which is less than ODOT's one $24 \%$ as shown in table 11 above.

\subsection{Lane Analysis}

Lane analysis followed on the conducted freight analysis. This was in an attempt to understand the concentration of the freight and non-freight mobility concentrations on the individual lanes and how this could have impacted on the freight traffic flow. The study was conducted on the three lanes of the station A roads. The total number of vehicles counted was 605,170 which 
encompassed both the freight and non-freight vehicle categories as represented in the table below. The freight vehicles categories on lane 1 were 35708 out of the total counted lane 1 vehicles which were 154,607 . This was 6 per cent of the freight vehicle category which translated to 23 per cent of the total number of vehicles counted. On Lane 2, the freight vehicle category was 42,791 out of the total counted 234,180 . This translated to 7 per cent of the total vehicles on the lane and 18 per cent of the total number of vehicles counted overall. Finally, in lane 3, 26008 bin 2, 3 and 4 vehicle categories, there were 26008 freight category vehicles out of the counted 216,383 total. Lane three had-in comparison with lanes 1 and 2, the least number of freight category of vehicles which was 4 per cent of the total number of vehicles counted on the lane and 12 per cent overall total of the counted vehicles. The difference in the counts signifies the fact that non-freight vehicle categories travel faster than freight vehicle categories. The freight vehicle categories (bin 2, 3 and 4) were the least on lane three because this lane, according to the America's road traffic rules, is the overtaking lane and the vehicles traversing this lane are usually at high speed which is not the characteristic of heavy vehicles. This explains why the overall concentration of freight vehicles on lane was generally higher in lane one than in lane two and three. Lane one is recommended for slow moving vehicles of which bin 2, 3 and 4 are. Figure 27 shows the lane analysis for an individual day July 2nd counts for all the categories, and the graph illustrates the same trends for the bin 2,3, and 4 categories where they were traveling on the freeway.

From the lane analysis, there was more non-freight category of vehicles going through lane 3 than in lane one per hour. The opposite was true for the freight vehicle categories. The hourly flow rate for the freight category of vehicles was slower from the perceived percentages. This was slowest for lane three for the same reason that freight carrying vehicles move slower than 
the non-freight vehicles. Vehicles using lane three are normally at a higher/overtaking speed than the vehicles going through lane one and two.

Table 12: Lane Analysis for Freight and Non-Freight Vehicles

\begin{tabular}{|c|c|c|c|c|c|c|}
\hline & \multirow{2}{*}{$\begin{array}{c}\text { Station } \\
185\end{array}$} & Lane 1 & Lane 2 & Lane 3 & & \\
\hline & & 154607 & 234180 & 216383 & & \\
\hline & \multicolumn{3}{|c|}{ Bin 1} & \multicolumn{3}{|c|}{ Bin $2+3+4$} \\
\hline & Lane 1 & Lane 2 & Lane 3 & Lane 1 & Lane 2 & Lane 3 \\
\hline Counts & 118899 & 191389 & 190375 & 35708 & 42791 & 26008 \\
\hline$\%$ of the Total Counts & $20 \%$ & $32 \%$ & $31 \%$ & $6 \%$ & $7 \%$ & $4 \%$ \\
\hline $\begin{array}{c}\text { \% of the Total Counts on } \\
\text { the Lane }\end{array}$ & $77 \%$ & $82 \%$ & $\mathbf{8 8 \%}$ & $23 \%$ & $18 \%$ & $12 \%$ \\
\hline
\end{tabular}

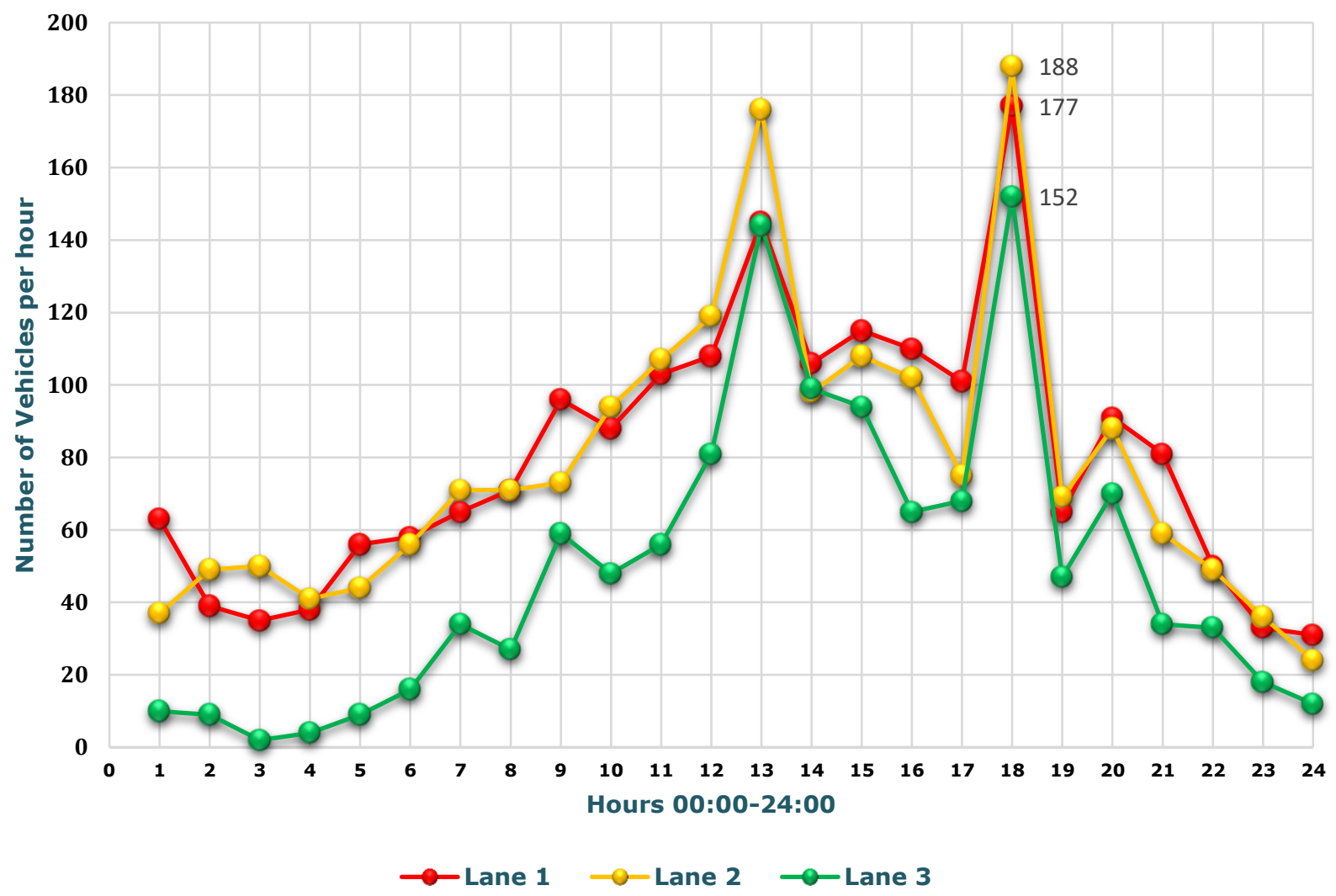

Figure 27: Lane Analysis, Station A, Bins 2, 3, 4 Counts at July $2^{\text {nd }} 2016$ 


\section{DISCUSSION}

As hinted earlier, Oregon State is characterized by a mixture of non-freight and freight mobility. The figures in the results section as analyzed supported this view. To begin with, from the findings, the number of vehicle counts for bin vehicle category sufficed as being more than bin 2 , 3 and 4 categories. This is to say that in both Station A and Station B, the traffic on the roads was mainly characterized with small vehicles. As reviewed in the literature, the Interstate 5 freeway is characterized with steep grades that happen to slow down most heavy vehicles where the bin 2, 3, and 4 categories lie. This could explain why there were relatively less counts along the roads for both the stations. It is possible that this characteristic of the freeway forces most of the truck drivers to avoid these paths for fear of delays and consequential congestions. It turned out from the results findings that there was a general higher trend of vehicle counts throughout the results at the beginning of the months when compared with the end of the month.

In Portland, the majority of the inhabitants are employed and work from 8 a.m. to 5 p.m. a higher percentage of the working class own personal vehicles and they prefer driving themselves to work for convenience sake. This explains why the high weekly bins 1 vehicle counts was highest in the early months since these are the times most of the population has earned and are capable of affording fuel for their vehicles. The same explains why during early mornings, the bin 1 vehicle counts were also highest. The trend was however not in conformity during weekends when most of the population doesn't work. Higher traffic counts for both the stations and for bin 1 case was evidenced later in the afternoons since these are the times most people probably drive along for recreation purposes. Traffic counts during the weekends were generally lower as compared to the weekdays since some of the populations are indoors unlike on weekdays when most of the population got to work. The Bin 2, 3, and Bin 4 vehicle 
categories illustrated an almost flat trend during the day with the lowest patterns during the weekends when compared to weekdays. It was earlier mentioned that Oregon is Freight dependent state. It has however turned out from the findings in this study that the non-freight mobility in the two studied stations of Portland is much higher than the freight mobility. This is to say that there are generally more personal vehicles on the road than there are freight vehicles. From this an insight could be projected that there are more congestions due from the bin 1 vehicle category than with bin 2, 3 and 4 respectively. An effective strategy for mobility monitoring of these vehicles is thus essential to safeguard the state's traffic mobility monitoring goals. As defined in the ODOT, some of the goals include effective conflict resolution by the truck and elimination of bridges that discourage trucks from certain streets as a result of their weight. The other ODOT goal is to minimize some of the PM and AM peak hour delays. These would effectively be realized if such data and information analyzed in this study were taken into serious consideration by the traffic planning teams.

From the lane analysis, there were more non-freight vehicles going through lane three than there were in lanes 2 and 1. This was explained to be due to the understanding that lane three accommodates high speed moving vehicles of which the freight carrying vehicles are not. The hourly flow of vehicles on lane 3 was consequently the highest as supported by table 12 above. 


\section{CONCLUSION}

The report explored freight mobility monitoring opportunities from the new length-based data. The Interstate 5 freeway guided the basis of the discussion. Some of the technologies for traffic monitoring were reviewed. The inductive loop technology emerged as the most recommended for a number of merits that were discussed. In the study, it sufficed that this technology could be adopted to collect traffic data to do with vehicle speed and count (among others) from moving vehicles and this information may be conveyed to various data analysis and storage platforms remotely. It was however pointed out that for accurate data collection, care must be taken whenever repair or calibration of the associated machinery is being done. The study proceeded further to analyze data for Portland North and South Stations with the aim of understanding the traffic flow of Portland city. From the findings, non-freight mobility dominates the Portland city of Oregon. This is true from the result findings that were realized from this study.

As analyzed from the metro atlas of Oregon, most people in the studied area were employed. Most of these most probably live above the poverty line and would be classified as the middle class considering their earnings. This also explains the possibility of there being more persona vehicles than trucks and freight vehicles. The city has already established road networks but from the traffic scenario analyzed, there may be need for further infrastructure development and more efficient traffic monitoring and planning.

As it was elaborated, understanding freight mobility of a given area would be so helpful in the infrastructure planning of a given location. In the figure number 5 above, it was also demonstrated that as per the current traffic plan of the city, the intersection gateways are normally characterized with heavy traffic flow and congestion especially during the peak hours 
like $1700 \mathrm{hrs}$ and $1800 \mathrm{hrs}$ unlike during the mid-days. This explains the reason why there was more freight mobility during mid-days than early mornings and late dawns. This is so because it is these main gateway roads that carry all the traffic onto the other transit roads. This also so because it is around this evening time when most people are rushing back to their residential spaces which are mostly and primarily interconnected through the gateway intersection points. It

is further explained and revealed that there is a huge work force inflow and outflow within Portland city which could probably be due to the large industrial spaces described above.

From the conducted lane analysis, there were more non-freight vehicles going through lane three than there were in lanes 2 and 1 . This was explained to be due to the understanding that lane three accommodates high speed moving vehicles of which the freight carrying vehicles are not. The hourly flow of vehicles on lane 3 was consequently the highest as supported by table 12 above.

\subsection{Recommendations for Future Analysis}

From the analysis of data, there could have been large discrepancies in the sensitivities of the detector values. A dual loop method of data collection would be most recommended for future studies. A further study may also be conducted using the DEDAC approach which is laptop based which would make it possible for the researchers to do adjustments on the loops' levels of sensitivity (Akcelik, 2011). This would significantly boost the system's efficiency as well as the accuracy. To add on this, the trends realized from this study may not have been exhaustive. This is considering that the study period spanned up-to one month which seemingly may be a short timeline for conclusive observations. From this, it is recommended that future related research works factor it the issue of time. 
A longer period would be more proposed if the long-term trend were anything to focus on. This way, it would be possible for the long-term goals and plans to be viable and sustainable too. For this concern to be factored in effectively, future growth and demand projections should also be modeled. Considering the uncertainties that are a characteristic of the future, it may practically be hard to accurately project the future trends for inclusion into the model. In such scenarios, computer based simulation models would suffice. In cases where doubts may be borne from the future demand predictions, a sensitivity analysis may be conducted over the demand value ranges in a bid to find out what impact the demand values may have. The projections of the models could be realized by first of all developing a base case model from which the plan would be developed. Some of the options available for the future would include suggestions for changes in the conditions of the traffic and the infrastructure networks at large. 


\section{REFERENCES}

1. Mobility Corridors Atlas. (2016). Retrieved November 17, 2016, from http://www.oregonmetro.gov/mobility-corridors-atlas

2. Traffic Detector Handbook, (1997). Institute of Transportation Engineers. Washington, DC, 2nd Edition.

3. Zhang, X., Y. Wang, and N. L. Nihan, (2003). Investigating Dual-Loop Errors Using Video Ground-Truth Data. Proc. ITS America.

4. Payne, J., and S. Thompson, (1999). Malfunction Detection and Data Repair for Induction-Loop Sensors Using I-880 Database. In Transportation Research Record: Journal of Transportation Research Board, No. 1570. National Research Council, Washington, D.C., pp 191-201. 4.

5. Nihan, N. L, (2002). Aid to Determining Freeway Metering Rates and Detecting Loop Errors. Journal of Transportation Engineering, Vol 123, No 6. ASCE, November/December 1997, pp454-458. 5.

6. Jacobson, L., N. L. Nihan, and J. Bender, (2011). Detecting Erroneous Loop Detector Data in a Freeway Traffic Management System. In Transportation Research Record: Journal of Transportation Research Board, No. 1287. National Research Council, Washington, D.C., pp151-166. 6.

7. Turochy, R. E. and B. L. Smith, (2000). A New Procedure for Detector Data Screening in Traffic Management Systems. Preprint CD-ROM. Transportation Research Board Annual Meeting. Washington, D.C., Paper no. 000842. 7.

8. Park E. S., S. Turner, and C. H, (2006). Spiegelman. Empirical Approaches to Outlier Detection in ITS Data. In Transportation Research Record: Journal of Transportation Research Board, No.1840. National Research Council, Washington, D.C., pp. 21-30. 8. 
9. Chen, L. and A. May, (2003). Traffic Detector Errors and Diagnostics. In Transportation Research Record: Journal of Transportation Research Board, No. 1132. National Research Council, Washington, D.C., pp 82-93. 9.

10. Coifman, B. (2010). Using Dual Loop Speed Traps to Identify Detector Errors. In Transportation Research Record: Journal of Transportation Research Board, No. 1683. National Research Council, Washington, D.C., pp 47-58. 10.

11. Coifman, B. (2002). Event Data Based Traffic Detector Validation Tests. Preprint CDROM. Transportation Research Board, Washington. D.C.,

12. Daily, D.J. and Z. Wall. (2003). An Algorithm for the Detection and Correction of Errors in Archived Traffic Data. Preprint CD-ROM. Transportation Research Board, Washington, DC,

13. Smith, B. and J. Conklin, (2013). The Use of Local Lane Distribution Patterns to Estimate Missing Data Values from Traffic Monitoring Systems. In Transportation Research Record: Journal of Transportation Research Board, No. 1811. National Research Council, Washington, D.C., pp 50-56.

14. Zhang, X., Y. Wang, N. L. Nihan, and M. E. Hallenbeck. (2005). Development of a System for Collecting Loop-Detector Event Data for Individual Vehicles. In Transportation Research Record: Journal of Transportation Research Board, No. 1855. National Research Council, Washington, D.C., pp 168-175.

15. Akcelik and Associates (2011). General Framework for Road Traffic Models.

16. Oregon Department of Transportation. Traffic Monitoring, Transportation Volume tables, from http://highway.odot.state.or.us/cf/highwayreports/traffic_parms.cfm. 